Revista lus et Praxis, Año 24, No 3, 2018, pp. 67 - 108

ISSN 0717 - 2877

Universidad de Talca - Facultad de Ciencias Jurídicas y Sociales

Sentido y límites de la inevitabilidad en el estado de necesidad Rodrigo Guerra E.

Trabajo recibido el 16 de septiembre de 2017 y aprobado el 8 de mayo de 2018

\title{
Sentido y límites de la inevitabilidad en el estado de necesidad FALTA SUBTÍTULO INGLÉS
}

\section{RODRigo Guerra E.}

\section{Resumen}

Un aspecto controvertido en el estado de necesidad es determinar cuál es la esencia de esta institución. Para estos efectos, en este artículo se realiza un estudio del requisito de la subsidiariedad, contemplado en la circunstancia segunda de la disposición del art. 10 № 11, esto es, que no exista otro medio practicable y menos perjudicial para evitarlo. Si bien dicho requisito se posiciona en la necesidad concreta, pareciera ser que puede ser parte de la abstracta a través de la inevitabilidad. Por ello, pretendemos demostrar cuándo la conducta del agente requiere de un único medio, en el caso de la necesidad abstracta, para estar amparada por el estado de necesidad.

\section{ABSTRACT}

The paper exposes a study of the subsidiarity requirement of the necessity defense, as well as its relationship to the article $10 \mathrm{~N}^{\circ} 11$ second circumstance. The subsidiarity requirement is theoretically founded through an interpretation of concrete necessity. However, it seems to be also part of Abstract necessity based on the inevitability. In this sense, the article attempts to identify when the agent conduct requires only a single mean, in the Abstract necessity case, to be covered by the necessity defense.

PalABRAs Clave

Inevitabilidad, defensa por repulsión, subsidiariedad, moderación

KEY WORDS

Inevitability, repulsion defense, subsidiarity, moderation

\section{Contexto y objetivos}

La dogmática nacional en el análisis del estado de necesidad suele centrarse en la naturaleza del art. $10 \mathrm{~N}^{\mathrm{0}} 11$, es decir, la manera en que deben ser comprendidos sus requisitos. Si bien esta materia se puede esbozar a propósito de la regulación mencionada, lo cierto es que la discusión respecto de su esencia no se ha tratado con detalle ${ }^{1}$. Ciertamente, la cuestión relativa a la esencia del estado de necesidad, esto es, qué es el estado de necesidad, en lo que concierne a una

\footnotetext{
* Abogado, Doctor en Derecho, Profesor de Derecho penal de la Universidad de Los Andes, Chile. Dirección postal: Facultad de Derecho, Universidad de los Andes, Monseñor Álvaro de Portillo 12.455, Las Condes, Santiago, Chile. Correo electrónico: rguerra@uandes.cl.
} 
doctrina que incida en su interpretación, requiere tratamiento. Como se conoce, las respuestas en el ordenamiento jurídico-penal chileno y español no son muy variadas. Así, por ejemplo, mientras en Alemania podemos observar que existe una gran variedad de posiciones, en Chile o España no se le ponen mayores exigencias al principio del interés preponderante ${ }^{2}$. Destaca en este sentido, en la dogmática nacional, el trabajo de Wilenmann, donde su tratamiento critica expresamente la comprensión del estado de necesidad a través del mencionado principio $^{3}$ e incluso realiza una propuesta alternativa que podría incidir en la comprensión del modelo de justificación $n^{4}$.

Estas diferentes compresiones -que curiosamente se dan a partir de regulaciones propias del modelo alemán- parecen responder simplemente a distintos desarrollos políticos, sociales y culturales que han dejado marcas en la interpretación de las causales de justificación, de modo que pueden ser compartidas o rechazadas en dichos términos. Sin embargo, este artículo no trata sobre esta cuestión. De lo que aquí se trata es de determinar si la inevitabilidad tiene algo que decir en la interpretación del estado de necesidad y, en caso afirmativo, en qué perspectiva y con qué consecuencias ${ }^{5}$. El interés por esta materia no es en absoluto contingente, pues se hace cargo de una tendencia ausente en la dogmática chilena, en orden a la resolución de casos de estado de necesidad.

Como se sabe, la creciente normativización que la dogmática ha sufrido en las últimas décadas, a través de las diversas respuestas en torno a qué es el estado de necesidad, ha terminado por alcanzar el ordenamiento jurídico

\footnotetext{
${ }^{1}$ En este contexto, si bien nos parece excesivo afirmar que toda la dogmática chilena ha posicionado "en el olvido la discusión sobre el fundamento [del estado de necesidad]", WilennanN (2014a), p. 220, la dogmática nacional no ha discutido lo suficiente sobre el fundamento del estado de necesidad, quizás es porque sostiene sus propiedades en una denominación que designa como elemento de realidad, WitTGenstein (1988), p. 81. Sin embargo, esta designación no implica dejar de indagar en los fundamentos de este razonamiento.

${ }^{2}$ Respecto de una panorama completo de la discusión, véase WilennmanN (2014a), pp. 220 y ss.

${ }^{3}$ En la doctrina chilena WILENMANN sostiene que "el principio del interés preponderante no parece ofrecer como fundamento del estado de necesidad justificante más que una tautología" en WILENMANN (2014a), p. 232.

${ }^{4}$ En este orden de ideas, se reconoce con énfasis la importancia del modelo contractualista de John Rawls en alusión a la ponderación de intereses en Merkel (2000), pp. 190-191. Por su parte, se entrega una descripción de la propuesta contractualista rawlsiana de Reinhart Merkel en PAwLIK (2002), pp. 67-69.

${ }^{5}$ En este contexto, no realizaremos un paralelo entre la cláusula de subsidiariedad del art. $10 \mathrm{~N}^{\circ} 7$ y el art. $10 \mathrm{~N}^{\circ} 11$, porque adherimos a la interpretación del $10 \mathrm{~N}^{\circ} 11$ realizada por Enrique Cury. El autor crea esta disposición con el objeto de abarcar tanto un efecto justificante como exculpante en el estado de necesidad. Así, consideramos que existe en la norma una tolerancia de la imprecisión. Tolerancia que contempla todos los supuestos del art. 10 № 7, véase CURY (2013), pp. 251-252; AcostA (2013), p. 697; Greenawalt (1986), p. 108.
} 
chileno. En el caso del estado de necesidad lo que llama la atención no es el ejercicio del método analítico, sino más bien la prórroga del mismo en torno a la inevitabilidad ${ }^{6}$. Como se ha puesto de relieve, como observaremos en el desarrollo de este artículo, es precisamente en el campo de la tradición moral clásica donde se dan las condiciones propicias para el tratamiento de la esencia del estado de necesidad.

En efecto, aun cuando no siempre de modo explícito, el recurso a las distintas variantes filosóficas del estado de necesidad ha servido tanto en España como en algunos países sudamericanos, entre ellos Chile, como argumento de justificación en las eximentes de responsabilidad. Y debe reconocerse que, en la medida en que dicha doctrina tiende a establecer patrones en la aplicación de la institución, la asociación parece a primera vista natural, con la secuela de que los partidarios de la tesis de la justificación a través del principio de solidaridad, no sólo deben enfrentarse a los partidarios del principio del interés preponderante, sino que además defenderse del reproche de argumentar desde los parámetros de su modelo ${ }^{7}$.

\footnotetext{
${ }^{6}$ Se puede observar un reconocimiento a esta propuesta analítica en torno a los rendimientos del estado de necesidad en la doctrina contemporánea en HRUSCHKA. Este autor, a modo de ejemplo, a propósito del estado de necesidad trabaja en diferenciar entre estado de necesidad absoluto (necessitudo simplex seu absoluta) y estado de necesidad con limitaciones (necessitudo cum adjunctione). Ello con el objeto de no confundir casos de vis absoluta con la plataforma conceptual del estado de necesidad. En esta línea, en el estado de necesidad absoluto nos encontramos frente a movimientos corporales sin volición; es decir, situaciones de vis absoluta. En cambio, el estado de necesidad con limitaciones responde a todos los casos que consideramos, actualmente, parte del estado de necesidad porque el agente tiene la posibilidad de decidir, véase HRUSCHKA (2005), pp. 200-201.

${ }^{7}$ Wilenmann plantea sostener el sistema de las justificantes desde el principio de solidaridad. Incluso llega a sostener que "la discusión respecto del fundamento del estado de necesidad muestra que cualquier tratamiento del estado de necesidad justificante y en general del sistema de derechos de necesidad requiere claridad, ante todo, respecto del conflicto que este supone. El concepto de solidaridad constituye una forma de designación de este conflicto -esta es su función sistemática-, antes que una forma de solución. Considerado de cerca, la solución del conflicto es, en realidad, interna a este y no simplemente externa. Con ello, pese al valor del mantenimiento de la distinción entre dos funciones del concepto de solidaridad, se trata en realidad de un concepto unitario", WILENMANN (2014a), p. 239. Para este autor, la solidaridad tendría una funcionalidad negativa y una de fundamentación en sentido estricto. La primera apuntaría a la "posición axiológica-sistemática de las instituciones determinadas por este (en materia penal ante todo estado de necesidad y omisión de socorro): son excepciones a la estructura general del derecho derivada de una comprensión individual de la autonomía", WILENMANN (2014a), p. 235. En cambio, la de fundamentación en sentido estricto, a "designar el conjunto de razones que fundamentan el reconocimiento de excepciones a la estructuración formal general del derecho en las condiciones fijadas por el estado de necesidad", WILENMANN (2014a), p. 235. Por su parte, se observa también una posición similar en Merkel (2000), p. 196. Respecto de los aportes de esta última postura en la dogmática penal, véase PAWLIK (2002), pp. 67-69. Por último, podemos indicar que WiLENMANn plantea un modelo, a propósito del estado de necesidad, en torno a la justificación, en WiLENMANn (2017).
} 
A continuación se pretende demostrar que la relevancia de la inevitabilidad en España y en Chile, no constituye consecuencia de la normativización de la subsidiariedad y que, más bien al contrario, puede ser el punto de partida de importantes objeciones a esta. Antes de realizar esta tarea es necesaria una precisión conceptual. La inevitabilidad es una teoría que pretende explicar el estado de necesidad y es únicamente relevante en la medida que se permita indagar en su sentido teleológico, puesto que se trata de una teoría que incide ya no desde los parámetros de la doctrina alemana, sino más bien de la italiana, con la consecuencia - de la mayor importancia práctica- de que su valoración permite delimitar los parámetros del ejercicio de la subsidiariedad en el estado de necesidad ${ }^{8}$.

La cuestión puede incidir en si la selección del medio menos lesivo, debe ser considerada parte de la esencia o naturaleza de la eximente, sólo en la medida en que la valoración de este factor se proyecte en el prius lógico del estado de necesidad. Pero entonces se trata de características y circunstancias propias de la subsidiariedad, definidas previamente en términos generales, y para cuya constatación la acción del agente, según las circunstancias particulares, es del todo relevante ${ }^{9}$. Si bien no todas las contribuciones observan en la inevitabilidad una relación con la subsidiariedad, en la medida en que se asocian a la selección del medio menos lesivo, para aceptar la concurrencia del estado de necesidad, será tratada aquí sin distinciones, remitida a la definición explicitada.

\section{Primeros indicios de la inevitabilidad}

Es habitual manifestar el hermético origen del estado de necesidad en la dogmática penal, aunque en varios cuerpos normativos de larga data se pueden observar rastros de esta institución ${ }^{10}$. Si bien no existe certeza de su comienzo, podemos indicar que sí lo hay en sostener su procedencia de la noción de

\footnotetext{
${ }^{8}$ Guerra (2017).

${ }^{9}$ Sentencia del TSE del 8-12-1987 (Ponente: Díaz Palos). Énfasis añadido. En esta línea, reconocen la inevitabilidad de forma expresa en el estado de necesidad, véase JIMÉNEZ DE AsúA (1961), p. 417; Morales (2007), p. 516; Morales (2011), p. 224. En el caso de Baldó existe una referencia indirecta al término por medio del concepto de necesidad concreta. Ello, porque trata la inevitabilidad desde su naturaleza operativa haciendo referencia a la cláusula de subsidiariedad. No obstante, enuncia este concepto haciendo referencia expresa a la sentencia del TSE del 3 de diciembre de 1987, que reconoce la inevitabilidad como parte de la esencia del estado de necesidad, véase BALDó (1994), p. 150, nota 334.

${ }^{10}$ Respecto del desarrollo de esta institución en el Decreto de Graciano, los Decretales de Grocio y la Constitutio Criminalis Carolina, véase García-RIPOll (2006), pp. 111-116. Por otra parte, en la Ley Josefina, la Constitutio Criminalis Theresiana y el CP de Galicia, Stooss (1913), pp. 133-135. Se puede observar una referencia de la evolución histórica de esta institución en diversos cuerpos normativos en JIMÉNEZ de Asúa (1961), pp. 293-305.
} 
necesidad $^{11}$, que repetidas veces se menciona en el Corpus Juris Canonici en los libros penitenciales, a través de diferentes modalidades del adagio necessitas legem non habet, en los delitos religiosos y el hurto famélico ${ }^{12}$.

En este contexto, algunos consideran la inevitabilidad parte de la noción de necesidad ${ }^{13}$, relación que se observa en sus inicios en el Derecho penal canónico, a propósito de la temática del homicidio ${ }^{14}$. Si bien dicho Derecho no era partidario en sus orígenes de la defensa privada, se mostraba partidario de la violencia por repulsión en el Decreto Graciano ${ }^{15}$. Así, en la defensa contra una agresión se diferenciaba entre una necesitas evitabilis e inevitabilis. La primera clase - necesitas evitabilis- no aceptaba la defensa cuando el ataque se podía impedir de otro modo, por ejemplo, con la huida de ser viable ${ }^{16}$. La segunda -necesitas inevitabilis- en cambio, permitía la defensa bajo cualquier circunstancia. La categoría limitaba la defensa a la presencia de una agresión ilegítima no posible de enfrentar de otra forma ${ }^{17}$. La doctrina más remota también diferencia entre necesitas evitabilis e inevitabilis, porque el agredido será

\footnotetext{
${ }^{11}$ Respecto de la vinculación de la necesidad con el término germánico Noth, a propósito de la regulación del necessitas non habet legem, véase WAGNeR (1648) ө. 4.; LAUDIEN (1713), p. 7, § IV.

12 Jiménez De Asúa (1961), p. 304.

${ }^{13}$ En la dogmática hispánica se enuncia de forma expresa la inevitabilidad como parte del concepto de necesidad tanto en el caso de la legítima defensa como en el estado de necesidad en JIMÉNEZ DE Asúa (1961), p. 417. En este sentido, en el caso de la legítima defensa, PessoA (2001), p. 125; RivacoBA y Rivacoba (1965), p. 267. Asimismo, representativa de la esencia del principio de subsidiariedad en el estado de necesidad, Morales (2005), p. 505. En el Common Law se le puede observar como uno de los requisitos propios de la defensa de Necessity (Duress of Circunstances) en CHILDS (2002), p. 168; Dobson (2002), p. 74.

${ }^{14}$ Quintano (1946), pp. 93-95; Jiménez de Asúa (1961), p. 31.

${ }^{15}$ Ius naturale est commune omnium nationum, eo quod ubique instinctu naturæ, non constitutione aliqua habetur, ut uiri et feminæ coniunctio, liberorum successio et educatio, communis omnium possessio et omnium una libertas, acquisitio eorum, quæ celo, terra mari que capiuntur; item depositæ rei uel commendatæ pecuniæ restitutio, uiolentiæ per uim repulsio, véase Gracianus (1140) Distinctio prima, C. VII. Quid sit ius naturale [Isidor. eod. c. 4]; JımÉNEZ DE AsúA (1961), p. 31. En la actualidad, la defensa por repulsión se considera más bien parte del estado de necesidad defensivo y no de la legítima defensa. Ello, porque en este último caso no existe una agresión ilegítima que posicione al agente en un estado preferente equivalente a la legítima defensa. Sobre todo considerando que en el estado de necesidad defensivo es posible lesionar a un inocente o imprudente en sus derechos, LöfFLER (1901), pp. 542 y ss.; Mañalich (2013a), p. 256, nota 181.

${ }^{16}$ Sin embargo, debemos indicar que esta idea presenta matices con el reconocimiento de la legítima defensa en favor de terceros, véase JIMÉNEZ DE AsúA (1961), p. 32.

${ }_{17}$ Respecto del uso de los conceptos de necesidad evitable e inevitable en el Derecho canónico, véase VerANI (1708), pp. 312, § 10, y 313, § 12; WAGner (1725), p. 27, e 12, nota a) y pp. 57-58, e 20, nota a). Por su parte, existen vestigios en 1672 de esta distinción en el Derecho natural, entre necesidad evitable e inevitable, en Wolff (1968), pp. 417-422, §§ 566-570.
} 
sancionado penalmente cuando, pudiendo sortear la muerte del agresor con su huida, resuelve de todos modos matar al agresor. Por otro lado, cuando el agredido pueda huir con vergüenza, inclusive en el caso de noble secular o un soldado, la eximente resultará inaplicable ${ }^{18}$.

Estas restricciones a la defensa, en la necesidad inevitable del Derecho canónico, se identificaron, con posterioridad, con la designación de moderamen inculpatae tutelae, reconocida en el pasaje de la defensa privada de la Suma Teológica de Santo Tomás. No obstante, esta designación haría ficticio el reconocimiento de la legítima defensa en la dogmática penal ${ }^{19}$, porque su ejercicio residiría el requerimiento de un ánimo defensivo, propio del fuero interno del agente, que provoque por efecto colateral la muerte del agresor. Posición interpretativa que se confronta a la lectura moderna que realiza un examen objetivo de la legítima defensa ${ }^{20}$.

Ciertamente, el enunciado moderamen inculpatae tutelae se introduce en la jurisprudencia canónica en 1210, cuando el Papa Inocente III tuvo que decidir la procedencia de la legítima defensa en el caso del sacerdote Laurentius, que encontró a un ladrón que estaba atracando la iglesia con una herramienta de jardinería ${ }^{21}$. Los vecinos fueron advertidos de la situación por los gritos del sacerdote y terminaron con la vida del ladrón con palos. Los jueces papales discurrieron en que si el ladrón había golpeado primero, el sacerdote estaba justificado en devolver el golpe. Los jueces citaron la jurisprudencia del Derecho romano, que estaba asentada en la jurisprudencia canónica, haciendo mención a la frase en cuestión ${ }^{22}$.

\footnotetext{
${ }^{18}$ Schiappoli (1905), pp. 735-736.

${ }^{19}$ La legítima defensa sería la última alternativa ante una agresión antijurídica porque intentaría compatibilizar, aparentemente, el ejercicio de esta con la prohibición absoluta de matar a otro, JIMÉNEZ De Asúa (1961), p. 32; Bascuñán (2004), p. 68, nota 43; Quintano (1946), p. 100. Así, el Derecho canónico de una necessitas inevitabilis pasó a una necessitas evitabilis que generó una interpretación de la moderamen in culpatae tutelae que hizo ilusorio el reconocimiento de la defensa, véase Guzmán (2010), p. 75; SCHIAPPOLI (1905), pp. 732-739. Por otra parte, se ha dudado que Santo Tomás utilizara el decreto moderamenin culpatae tutelae para sostener sus argumentos de la legítima defensa en la cuestión 64 , art. $7^{\circ}$, II-II, de la Suma Teológica porque habría supuestamente ignorado la parte más fundamental del decretal que consiste en que la legítima defensa nunca justifica la venganza. Tomás de Aquino cita también esta frase en la Suma en II-II, cuestión 60, a. 6 ad 2. Interpretación que se sostiene en Pennigton (2013), p. 41, nota 52.

${ }^{20}$ KINDHÄUSER (2013), p. 71.

${ }^{21}$ Pennigton (2013), p. 40; Roumy (2006), p. 302.

${ }^{22}$ Los jueces papales también consideraron si Lawrence habría dado el golpe final o si podría haber animado a los habitantes del pueblo a atacarlo. El tribunal también debió determinar la fuerza del golpe y dónde impactó en el cuerpo del ladrón. Los médicos declararon que el golpe inicial no fue fatal, véase PENNIGTON (2013), pp. 40-41.
} 
Al referirse a la legítima defensa, el Derecho canónico alude a una defensa necesaria, entendiendo por tal aquella que se ejecuta con el propósito de salvar la propia vida. Pues bien, en el caso del ladrón que accede, en medio de la noche, a una morada, justifica al dueño para que le dé muerte. Se distingue entre el ladrón que ingresa a la morada durante el día y aquel que lo hace durante la noche, porque en esta hipótesis existe un peligro mayor. En esta última situación, se justificaría dar muerte al ladrón, porque dificulta a la víctima la posibilidad de oponerse a la agresión ${ }^{23}$.

De este modo, la expresión moderamen inculpatae tutelae admite que el agente enfrente la agresión del ladrón por medio de la violencia, porque en el Derecho canónico, esta acción es de Derecho natural. La defensa necesaria se debela en una la violencia que, a su vez, debe ser física y genera un daño concreto en el ladrón ${ }^{24}$. Esta expresión admite que sería legítimo resistir la fuerza con la fuerza, siempre que dicha acción se ejecute en oposición a un ataque ilegítimo. Además, el peligro que se quiere impedir debe ser actual, pues de lo contrario estaríamos en un caso de venganza y no de legítima defensa. Si la agresión puede sortearse sin matar al ladrón, no será permitida, como sucedería de existir la posibilidad de escapar ${ }^{25}$.

No obstante lo anterior, posteriormente aparece en la doctrina la posibilidad de no equiparar la alternativa de huir con una limitación al homicidio. Esta doctrina se desglosa de la Clementina de Covarrubias, relativa al homicidio. El autor acepta en la escolástica una perspectiva diferente a la doctrina antecesora, porque sostiene la alternativa de que el agredido, aun teniendo la posibilidad de escapar, mate al agresor. Pues bien, en estos términos la fuga no puede estimarse una defensa, ya que se genera lo opuesto: quien escapa no enfrenta fuerza con fuerza, sino que resguarda su propia vida ${ }^{26}$.

Ahora bien, en el estado de necesidad los canonistas, ante la contraposición entre la ley religiosa y la acción, admiten que la necesidad vuelve lícito lo que para la regla de conducta era ilícito, en atención a la expresión: la necesidad no conoce ley (necessitas legem non habet) ${ }^{27}$. Expresión que se aplica por la

\footnotetext{
${ }^{23}$ SChiappoli (1905), p. 733.

${ }^{24}$ SChiappoli (1905), p. 733.

${ }^{25}$ SCHIAPPOLI (1905), p. 734. En este sentido, la expresión moderamen inculpatae tutelae si bien tiene relación con rechazar o repeler fuerza con fuerza, su fundamento más que en "la caridad [...] [se encuentra] en los deberes para con nosotros mismos y para con la especie humana en general", FERNÁNDEZ (1966), p. 45.

${ }^{26}$ SChiAPPOLI (1905), p. 736.

${ }^{27}$ Schiappoli (1905), p. 736. En el caso del Derecho canónico, el aforismo en cuestión actúa como una atenuante del hurto, sin lograr exonerar a su autor, donde la necessitate famis aut nuditatis o restitución
} 
posición dominante en la escolástica en relación al conflicto entre el derecho a la vida y la propiedad, con independencia de que con posterioridad tenga rendimiento en el homicidio de inocentes en casos de necesidad ${ }^{28}$.

\section{Incidencia del moderamen inculpatae tutelae en la legítima defensa y el estado de necesidad}

El análisis de la expresión moderamen inculpatae tutelae es complejo y requiere determinar previamente cuál es la importancia de su examen históricofilosófico. Dicha expresión, en realidad, es resultado de un entramado de ideas en torno a la legítima defensa y el estado de necesidad. Por ello, es necesario realizar una revisión vinculada a la filosofía e historia. Esto con el objeto de hacer distinciones que sean coherentes con la evolución conceptual de los términos que rodean la expresión. Es decir, este examen está centrado en ilustrar cómo nos pueden ayudar los clásicos en la comprensión del derecho penal actual ${ }^{29}$.

En la ciencia jurídico penal, la metodología, tal como se desarrolla en el mundo académico, manifiesta la importancia de desentrañar tradiciones filosóficas que inciden en su objeto de estudio: el estado de necesidad ${ }^{30}$. Así, una dogmática que quiera dejar la evolución de los conceptos en este campo del conocimiento, nos parece incompleta. Dicha evolución "se expresa, sobre todo, en el lenguaje, especialmente a través de la terminología que emplea la filosofía" ${ }^{\prime \prime 1}$. Pues bien, el análisis de la expresión (moderamen inculpatae tutelae) no trata sobre una mera discusión formal en relación a los términos, sino que

del objeto robado excluiría la pena. Sin embargo, en casos de necessitas multum cogens o necesidad extrema la doctrina aceptó la impunidad total. Esta impunidad sobre la necesidad extrema se ha transformado en una verdadera fuente del Derecho a la que pueden recurrir aquellos que carecen de medios de subsistencia con el fin de proveérselos mediante la propiedad ajena. Por su parte, un sector minoritario aceptó dentro de la necesidad, hipótesis no relacionadas con la afectación de la propiedad. Así, en los casos del suicidio para defender la castidad, en el matar a otra persona para conservar la vida y en el adulterio por la impotencia del marido, estos se consideraban excusados, véase SCHIAPPOLI (1905), pp. 741-742; JiMÉNEZ de AsúA (1961), p. 305.

${ }^{28}$ En esta línea, como se sostiene en la Clementinam. Si furiosus. De homicidio, de Covarrubias, "extrema necessitas non tollit malitiam actus homicidio [...]", véase Covarrubias (1594), p. 480. Ello, con independencia de que otros autores de la Escuela de Salamanca matizaran la máxima en situaciones de guerra, García-Huidobro y Miranda (2013).

${ }^{29}$ Se puede observar (es dable encontrar ¿) esta metodología de trabajo en HrusCHKA (2006).

${ }^{30}$ Se puede observar la importancia de esta tarea en WILENMANN (2014), p. 239. También se puede observar (es posible encontrar) la busca de correlacionar la comprensión del estado de necesidad en corrientes filosóficas en JiMÉNEZ dE AsúA (1961), pp. 326 y ss.

${ }^{31}$ SIMON (1977), p. 7 
determina su verdadero sentido. A continuación, trataremos algunas de estas interpretaciones y cómo se insertan en la disciplina del derecho penal.

Gracias a la expresión moderamen inculpate tutelae hablamos de los límites por exceso en el ejercicio del estado de necesidad y la legítima defensa. $Y$ estos se asignan en su regulación, no únicamente como reglas propias de su naturaleza, sino además como meritorias en lo que concierne a excesos por falta de subsidiariedad y proporcionalidad. En efecto, en la doctrina nacional, el proceso de significación de la expresión, se ve inmerso en el tratamiento de la legítima defensa, lo cual implica que la limitación del exceso, es su origen y adquiere perspectiva en función de la regla de comportamiento que hace admisible el comportamiento.

Con mayor precisión, Bascuñán sostuvo que la teología moral de Tomás de Aquino en el pasaje de la defensa privada, en la cual se recoge la expresión moderamen inculpatae tutelae ${ }^{32}$, pretendió eludir el hecho de que no existe una prohibición absoluta de matar ${ }^{33}$. De acuerdo a este autor, según esta teoría, un mismo acto puede producir dos efectos: uno intencionado y el otro no. El agente pretende la autoconservación a través de la legítima defensa, desglosándose de ésta un efecto colateral no intentado: la muerte del agresor. Efecto ilícito no intentado que debe ser proporcionado al efecto lícito intentado: la autoconservación a través del ejercicio de la defensa. Última hipótesis, en la cual la licitud del efecto bueno envuelve el efecto malo.

Para Bascuñán, que los actos residan en la intención "es una concepción subjetiva extrema de calificación de la licitud del acto" ${ }^{\prime 34}$. En este sentido, cuando la muerte es consecuencia necesaria del acto de defensa, ese resultado está comprendido en una intencionalidad aparejada a la finalidad defensiva ${ }^{35}$. Por ello, no se puede sostener la justificación del acto en consideraciones meramente subjetivas. La situación defensiva debe observarse objetivamente para determinar su justificación, siendo prudente exigir únicamente su conocimiento para justificar la muerte del agresor. Sin embargo, exigir una especial motivación defensiva es excesivo por razones de justicia política ${ }^{36}$.

\footnotetext{
32 Sото (1968), p. 402, Lib. V, q. 1. art. VIII.

${ }^{33}$ BASCUÑÁN (2004), p. 68, nota 43.

${ }^{34}$ BASCuÑán (2004), p. 68, nota 43.

${ }^{35}$ A propósito de casos de estado de necesidad, Hörnle sostiene que: "no hay que profundizar más en esto. Aun cuando se puedan poner de manifiesto diferencias entre intención y conocimiento seguro, éstas carecen de relevancia en relación con el injusto superior que radica en un homicidio cometido 'solamente' con conocimiento', Hörnle (2010), p. 11; TADROS (2005), pp. 231 y ss.

${ }^{36}$ BASCUÑán (2004), p. 68, nota 43. En general la doctrinal nacional, véase Couso (2011a), p. 222.
} 
Línea de interpretación subjetiva de la legítima defensa que en la escolástica sustentó Cayetano, quien interpretó el pasaje de Santo Tomás, presente en la Suma Teológica, relativo a la defensa privada occisiva, desde el voluntario indirecto. Cayetano estimó que no era posible intentar intencionadamente la muerte del malhechor, pues ésta sólo puede ser una consecuencia del fin necesario de conservar la propia vida. Por ello, la muerte del agresor o efecto malo, puede ser sólo praeter intentionem; es decir, la muerte del agresor no puede ser querida como fin o medio ${ }^{37}$.

Esta interpretación de Cayetano llevó a la doctrina penal a rechazar la aplicación de la denominada moderamen inculpatae tutelae en la legítima defensa, porque de ella se desprendería que el agente debe preferir huir antes que confrontar al agresor e incluso la muerte de este únicamente podría darse por un efecto colateral de la defensa. Por ende, no sería lícito tener la intención deliberada de matar al enemigo, porque la finalidad de la acción es la autoconservación ${ }^{38}$. Aceptar la posición de Cayetano, efectivamente, retrotraería la dogmática penal hasta antes de Berner, porque reclamaría al agente el actuar en su fuero interno con la intención de defenderse y no con la finalidad deliberada de matar al agresor. De ahí que uno de los aportes de Berner a la dogmática ha sido apreciar la legítima defensa en una perspectiva objetiva, distanciándose de exigencias psicológicas concernientes al fuero interno de la víctima ${ }^{39}$.

Por tanto, exigir la inevitabilidad en la legítima defensa pareciera restringirla de "todo contenido humano" ${ }^{40}$. Posiblemente, la doctrina penal por esta razón rescata los aportes de la tradición escolástica únicamente en lo que respecta al

\footnotetext{
${ }^{37}$ En este contexto, Cayetano explica el pasaje tomista de la defensa propia afirmando la imposibilidad de querer la muerte del enemigo como un medio para defenderse de él. Así, la muerte de este únicamente es praeter intentionem; esto es, un efecto malo que no puede ser querido como fin o medio, $\mathrm{V} ı$ (1773), parte II-II, q. 64, a, 7; MIRANDA (2014), p. 59. Se ha criticado que esta lectura "encierra una oscuridad metafísica", porque el agente puede elegir el medio que estima necesario para conseguir la defensa, Sото (1968), p. 402, Lib. V, q. 1, art. VIII. Desde la perspectiva del doble efecto en la legítima defensa, la muerte del malhechor o adversario es per accidens y no intentada per se. Se considera que esta defensa es lícita si se ejerce con moderación. La muerte del adversario será un efecto colateral y no intentado que viciaría el acto, véase García (1990), p. 100.

${ }^{38} \mathrm{VIO}(1773)$, parte II-II, q. 64, a. 7.

39 Berner (1898), p. 107; KindHÄUSER (2013), p. 71.

${ }^{40}$ Quintano (1946), p. 100. Esta idea de configurar la legítima defensa como un derecho a matar fue recogida por la Novísima Recopilación. No obstante, esta perspectiva extensiva buscó ser moderada en el Derecho eclesiástico exigiendo una necesidad inevitable, véase QuiNTANO (1946), pp. 93-95. Sin embargo, podemos observar que Pessoa, al tratar la legítima defensa, insiste en sostener que la agresión ilegítima debe ser inevitable. Si la persona puede eludir la situación escapando del lugar, debe preferir dicha alternativa. Sin embargo, Pessoa modera su posición indicando que no puede exigírsele al agente hacer uso de esta vía de resultar "totalmente irracional y por lo tanto injusto", PessOA (2001), p. 125.
} 
hurto famélico en el estado de necesidad. Sin embargo, el precepto de la moderamen inculpatae tutelae requiere una lectura más meticulosa, porque existió una fuerte posición en la Escuela de Salamanca que no respaldó lo expuesto por Bascuñán ${ }^{41}$. Así, Domingo de Soto estableció que la expresión moderamen inculpatae tutelae contempla la intención directa de matar al agresor, incluso siendo lícito "buscar con la espada la garganta del enemigo"42. Más aún, este autor afirmó que "quien ve a un enemigo dirigirse directamente a él con la espada desenvainada, y teme no poder defenderse llegados a las manos, puede desde lejos derribarlo en tierra disparándole una flecha o arrojándole otro objeto. Esto quiere decir cum moderamine inculpatae tutelae. Por consiguiente el pensamiento de Santo Tomás es claro, y sencillamente natural $[\ldots]^{\prime \prime 43}$.

Soto sostuvo que si bien se puede considerar huir, herir o solicitar la paz al enemigo, antes que matarlo, "no hay razón [...] que imponga la obligación de atender a tantas dificultades, ya porque la condición del agredido, una vez que otro le hace injuria, merece ser favorecida [...]". Por ello, la categoría de moderamen inculpatae tutelae no puede ser interpretada desde una necesidad inevitable carente de todo contenido humano. Incluso Soto es crítico de la posición de Cayetano, indica que esta "encierra [una] oscuridad metafísica" ${ }^{44}$. Oscuridad que se identifica en el hecho de que es lícito dar muerte al enemigo para defenderse, pero es ilícito elegir "la muerte [...] como un medio"45. Soto señaló que de "la elección del medio que se cree necesario se sigue la voluntad decidida a conseguir el fin $[\ldots]^{\prime \prime 46}$.

La defensa propia del agredido merece ser favorecida si existe la posibilidad de elegir la muerte como un medio. Se observa una correlación entre la posición que sustenta Bascuñán en la legítima defensa y la lectura que realizó Soto de la moderamen inculpatae tutelae ${ }^{47}$. Esta expresión también la rescata

\footnotetext{
${ }^{41}$ Escuela que no podemos dejar de considerar al pronunciarnos sobre el principio del doble efecto, porque ésta, considerando los postulados tomistas, distingue entre aquellas acciones en que se busca intencionalmente matar a un inocente de aquellas acciones en que dicha muerte es un efecto colateral de la acción de defensa realizada, véase García-Huidobro y MiRANDA (2013), pp. 354-357. Asimismo, respecto de la importancia de Domingo de Soto como cofundador de la Escuela de Salamanca junto con Vitoria, véase Contreras (2013), p. 666.

42 Soto (1968), p. 402, Lib. V, q. 1, art. VIII.

${ }^{43}$ Sото (1968), p. 402, Lib. V, q. 1, art. VIII. Énfasis añadido.

${ }^{44}$ Sото (1968), pp. 402-403, Lib. V, q. 1, art. VIII. Énfasis añadido.

${ }^{45}$ Sото (1968), p. 402, Lib. V, q. 1, art. VIII.

${ }^{46}$ Soto (1968), p. 402, Lib. V, q. 1, art. VIII.

${ }^{47}$ Sото (1968), p. 402, Lib. V, q. 1, art. VIII. Los maestros de la Escuela de Salamanca del siglo XVI siempre tienen a la vista el trabajo de Cayetano, realizando muchas referencias a este entre sus citas. Sin embargo, se puede observar que en diversas ocasiones disienten de su opinión, como en el caso de
} 
Berner en su obra De impunitate propter summam necessitatem proposita, en la que planteó dos cuestiones fundamentales: la primera es si a un tercero le es lícito, en favor de alguien que es oprimido por alguna necesidad, ofender el derecho de propiedad, y la segunda es si se puede dar un derecho de defensa "jus defensionis (moderamen inculpatae tutelae)" 48 a quien es afectado en su derecho patrimonial por una agresión calamitosa en estado de necesidad.

Berner consideró que en el primer caso se puede impunemente (impune posse) actuar en favor de un tercero cualquiera, relacionado o no al agente, en una situación de peligro grave para la vida o la integridad física de aquél, ofendiendo la propiedad ajena. Pero en el segundo consideró que no compete (non competere) otorgar un derecho de defensa de la propiedad (ius defendendae proprietatis) respecto de una agresión legítima no culpable (distinguiéndolo de la legítima defensa) ${ }^{49}$.

Pero donde realmente se reconsideró el uso de la expresión, tanto en el campo del estado de necesidad como en la legítima defensa, es en Carrara ${ }^{50}$, quien en su Programa de Derecho Criminal consideró que en ambas situaciones la conducta no es punible, aunque se genere un hecho contrario al ordenamiento jurídico-penal, si presenta los elementos esenciales de la moderamen inculpatae tutelae o necesidad ${ }^{51}$. Para Carrara, las dos figuras se basan en la misma regla fundamental: no haber excedido los respectivos límites, tanto en el obrar (estado de necesidad) como en el reaccionar (legítima defensa), en atención a lo que requiere la necesidad de salvarnos. Aunque puedan variar los requisitos entre estas figuras, debemos remontarnos "hasta la máxima de que todo derecho tiene por contenido necesario la facultad de su propia defensa" ${ }^{\prime 2}$.

Fundamento de la facultad de la propia defensa que Carrara desprende de la obra de Tissot de 1875, en la cual éste sostuvo que los derechos podían ser

Sото respecto de la legítima defensa, e incluso lo impugnan, caracterizándolo "de oscuro, de ilógico, de imaginativo e ingenioso", BARRIENTOS (1998), p. 97.

${ }^{48}$ Por ende, la inevitabilidad no restringe la existencia de la necesidad, salvo en los casos de un exceso extensivo, MIR (2011), p. 448.

${ }^{49}$ Berner (1861), p. 13.

${ }^{50}$ BeRNer (1861), pp. 14-15.

${ }^{51}$ La inevitabilidad en el estado de necesidad tiene su origen en la doctrina penal de Carrara, JIMÉNEZ De Asúa (1995), p. 206; Carrara (1988), p. 209, § 302. Por su parte, Pacheco en la legítima defensa consideró respecto de la expresión cum moderamine inculpatae tutelae que, en torno a la necesidad racional del medio empleado, esta expresión técnica aludía a "cuando nos basta desarmar un agresor, y podemos desarmarle, no tenemos derecho para herir. Cuando le hemos herido e imposibilitado de dañarnos más, no tenemos derecho para matarle", PACHECO (1888), p. 152. Sin embargo, éste no se pronunció respecto de los efectos de la misma en el estado de necesidad.

${ }^{52}$ CarRara (1988), p. 200, § 287. 
relativos a las necesidades físicas de aplicación primaria y de adquisición derivada. Estableciendo que los derechos son aquellos relativos a la conservación de la vida, la salud, la inviolabilidad de la persona, el derecho de procurarse los alimentos, la vestimenta, un techo y los medicamentos. Derechos que se deben adquirir en medios de bienestar y perfeccionamiento para disponer libremente de ellos.

Tissot, respecto del derecho de proteger la vida o la persona contra injusta agresión, sostuvo que la inviolabilidad de la existencia humana tiene por derecho la defensa, cuyo límite de inflexión está determinado por la magnitud del ataque. La libertad exterior forma parte del derecho de la inviolabilidad de las personas. Nadie puede, en virtud de la naturaleza humana, atentar lícitamente contra la vida de otro. La agresión da derecho a defenderse por todos los medios necesarios, lo que provoca que se diga que el derecho a la defensa es infinito ${ }^{53}$. La persona humana no debe servir de instrumento, porque cada uno de nosotros debe ser respetado como un fin en sí mismo. Ningún tratamiento despectivo debe ser aceptado. Por consiguiente, el Derecho natural en un sentido estricto, considerando el derecho de inviolabilidad de la persona, al comprender la dignidad del hombre, puede defenderla por todos los medios necesarios, incluso a través de la muerte del agresor si fuese absolutamente necesario ${ }^{54}$.

También Tissot estableció que el derecho, desde que existe, es entero y absoluto. Entrega la facultad de hacer todo lo necesario para que sea respetado. En este campo del derecho la moral es menos severa, porque se regula sobre las consideraciones del sentimiento, más que las de estricta equidad. La inviolabilidad de la persona comprende la libertad exterior necesaria para que ejerza todos sus otros derechos. De ahí que la pregunta por la existencia de tales derechos y la comprensión de estos en un género sea incontestable ${ }^{55}$. Es fácil advertir que aquí no se está hablando de la equidad en un sentido estricto, o siquiera de la moral como un criterio de aplicación de la sanción, sino únicamente de la defensa de un derecho que resguarda la inviolabilidad de la persona humana, de donde nacen el resto de los otros derechos; es decir, de la necesidad en su mayor grado de abstracción.

En suma, no es dable exigir moderación al agente que actúa en estado de necesidad en el caso de la tabla. Pero tampoco es posible sostener a partir de este caso, una regla general que suprima por completo la moderación en el estado de necesidad. Así, pareciera ser posible erradicar la moderación sólo

\footnotetext{
53 Tissot (1875), р. 285.

54 TissOt (1875), р. 285.

55 Tissot (1875), р. 286.
} 
en el supuesto de que exista un peligro cierto de muerte y no haya otro camino para enfrentarlo. De lo contrario, no tendría sentido hablar de una cláusula de subsidiariedad, en el estado de necesidad que se considera uno de los principios subyacentes a este que, consagrado tácitamente en la segunda circunstancia del art. $10 \mathrm{~N}^{\circ} 11$, dispone que no concurra otro medio practicable y menos perjudicial para evitarlo.

\section{Límites a la defensa en el estado de necesidad}

Se puede afirmar con certeza que la moderación es un elemento que está presente tanto en la legítima defensa como en el estado de necesidad. Sobre esta base la moderación adquiere matices que responden a la idea de que no es posible exigirla cuando el agente actúa para evitar un peligro cierto de muerte. Sin embargo, no es posible -a partir de estas consideraciones- establecer una regla general que suprima por completo la moderación en el estado de necesidad. Así, pareciera ser posible erradicarla sólo en el supuesto de que exista un peligro cierto de muerte y no exista otro medio menos lesivo para enfrentarlo.

En las secciones que siguen, en este tercer apartado, expondremos algunas consideraciones de los resultados obtenidos en nuestra investigación histórica. Éstos reafirman, en gran medida, que la moderación aporta consideraciones relevantes para la compresión del estado de necesidad y la legítima defensa. Pero muestra también que se han omitido estas consideraciones en la dogmática actual, principalmente en el tratamiento desarrollado por algunos autores de la escolástica y la dogmática. Aunque compartimos la tesis histórica de que la existencia de la inevitabilidad se inicia con Carrara (incluso en el caso de que éste no haya pretendido formularla como lo pretendemos en esta investigación), pensamos que es importante examinar su origen para comprender las ideas modernas que están implícitas en ésta.

\subsection{Presencia de límites en Domingo de Soto y Suárez}

Todo este panorama cambia cuando entran en el espectro de los límites a la defensa en el estado de necesidad y la legítima defensa, las consideraciones de Domingo de Soto. Como es sabido, éste estableció que existen casos en los que el agente se podría anteponer a la acción de su enemigo aniquilándolo, considerando la fuente de peligro que es para su persona. Enunció el caso de quien encontrándose imposibilitado de salir de una aldea, debe irremediablemente enfrentar a su agresor o que viviendo con eéte (en la misma casa) tiene la certeza de que le dará muerte en algún momento ${ }^{56}$.

\footnotetext{
${ }^{56}$ Sото (1968), p. 403, Lib. V, q. 1, art. VIII.
} 
También consideró el caso de aquella mujer inocente que, acostada en la misma cama del marido, sabe con certeza que la matará cuando duerma. Acción que ejecutará con la espada que esconde bajo la almohada. Situaciones de peligro en las que pareciera ser que el agente podría adelantarse para aniquilar a su enemigo ${ }^{57}$. Soto sostiene que la facultad de aniquilación del enemigo en estos casos parece dudosa, pues si el acto del agente es constitutivo de agresión, es ilícito; pero si es de defensa, no puede condenársele. Estos "no puede[n] determinarse por la ley, ni por la ciencia, sino en cada caso en particular ha de juzgarse según el arbitrio del prudente" ${ }^{\prime \prime 5}$.

Conjeturas que podríamos identificar en el estado de necesidad en la situación del tirano familiar, que en cualquier momento despertarse matando a su mujer u otro integrante de la familia ${ }^{59}$. En estos casos hay razón de imponer mayores obligaciones, atendiendo a la mayor cantidad de dificultades que presentan, porque es difícil que la condición del agredido sea favorecida desde su inicio como en la legítima defensa ${ }^{60}$. Aquí Suárez, a propósito de casos de extrema necesidad, dentro de la escolástica, también se pregunta en qué ocasiones la ley obliga ante situaciones de peligro de muerte (periculum mortis).

Suárez reconoció que es difícil establecer una norma en estos casos, debiendo prudencialmente resolverse; sin embargo, realizó observaciones fundamentales $^{61}$. El peligro o temor de muerte (metum mortis) puede darse por medio de

\footnotetext{
${ }^{57}$ Sото (1968), p. 403, Lib. V, q. 1, art. VIII.

${ }^{58}$ Sото (1968), p. 403, Lib. V, q. 1, art. VIII.

${ }^{59}$ Roxin (1997), p. 712; VILLEGAS (2010). No obstante, algunos consideran que el caso del tirano familiar es una situación de legítima defensa preventiva, porque el tirano constituye una agresión potencial de inminente realización. Así, avanzar con un garrote con el objeto de lesionar o tomar un arma con la intención de disparar son actos constitutivos de una agresión ilegítima, PESSOA (2001), pp. 108, 118-119; Requejo (1999), pp. 129 y ss. Por su parte, reconociendo situaciones próximas a la legítima defensa, en el caso del tirano familiar, se sostiene que "debe apreciarse una disminución del contenido de peligrosidad del hecho imputable a la esfera de competencia del autor (o, además, la disminución de la culpabilidad de éste). Más que de una culpabilización de la víctima, se trata, de nuevo, de hacer responsable al autor tan sólo por lo que ha realizado efectivamente y en la medida en que es culpable por ello" en Silva (1998b), pp. 188-189.

${ }^{60}$ Este debate tiene lugar con el caso de Judy Norman, a partir del cual se comienza a discutir en el modelo norteamericano el rol de la inminencia en la legítima defensa, respecto de aquellas situaciones en que la mujer decide dar muerte al tirano familiar, que en nuestro sistema actualmente se traduce en una figura de estado de necesidad exculpante y con anterioridad a la introducción del art. $10 \mathrm{~N}^{\mathrm{0}} 11$ se resolvía por el miedo insuperable y la fuerza irresistible.

${ }^{61}$ Las preguntas de Francisco Suárez son importantes en esta materia, porque es uno de los principales miembros de la Escuela de Salamanca que, conjuntamente con Domingo de Soto, se pronuncia acerca de casos de extrema necesidad. Perspectiva que no está impregnada de una visión subjetivista que
} 
un modo extrínseco e intrínseco (periculum mortis, vel est ab intrinseco, vel ab extrinseco $)^{62}$. La idea intrínseca proviene de la frágil naturaleza humana, sea por sed o hambre. La extrínseca puede proceder de una tempestad, la guerra o cualquier otra causa externa que no pretende la infracción directa de la ley. La primera se denomina "accidental respecto de tal efecto; la segunda [...] natural [...] procedente de una causa que produce tal temor"63 (tale metum).

En la primera situación, según el planteamiento de Suárez, propia a las formas intrínsecas del peligro de muerte, normalmente la ley positiva no obliga al agente en la situación de peligro ${ }^{64}$. En la segunda situación, "el temor [...] normalmente no excusa de la ley, porque cede en desprecio de la fe o la religión" 65 . El autor indicó en los dos casos "normalmente [,] porque no existe regla tan general y segura que no puede fallar una vez, y por tanto, para formar el juicio definitivo, siempre hay que atender a las circunstancias particulares de cada caso" ${ }^{\prime \prime 6}$. Luego, seguramente con pretensiones científicas, indicó que en el segundo caso, relacionado con el desprecio de la fe o la religión, puede ser que la acción no se realice con el objeto de transgredir o despreciar la ley positiva, sino "por otras causas humanas de placer o de utilidad"67. Casos en los cuales el temor (metus) proveniente de una causa intrínseca o extrínseca no provoca "un desprecio de la ley u otro mal semejante"68.

En los casos de necesidad extrema se vuelve complejo diferenciar la licitud o ilicitud de la defensa, porque no existiría -aunque no lo indicó el autor- una agresión antijurídica. El razonamiento tanto de Suárez como Soto nos parece que no difieren de los problemas que subsisten en torno al estado de necesidad referente a la moderación, por la distinción de peligros extrínsecos e intrínsecos que realizó Suárez y el reconocimiento de agresiones potenciales en el caso de Soto.

imposibilita toda acción del agente. Respecto del importante atractivo de Suárez en el Siglo de Oro, en lo relativo a la defensa del voluntarismo jurídico, véase Contreras (2013), p. 660.

${ }^{62}$ Asimismo, es posible encontrar una referencia a estas modalidades extrínsecas e intrínsecas, a propósito de la necesidad evitable e inevitable, en Martínez (1870), p. 334.

${ }^{63}$ SuÁrez (1967), p. 329, Lib. III, Cap. XXX, 9.

${ }^{64}$ SuÁrez conecta estos casos de peligro intrínseco con la fragilidad humana. Sin embargo, esta fragilidad no tiene relación con el razonamiento de la en la sentencia del 11 de marzo de 1927 del Reichsgericht que dio lugar al aborto terapéutico. Fragilidad humana que se vincula con una compasión ilimitada del legislador, véase Giuliani (1970), pp. 114-115.

${ }^{65}$ SuÁrez (1967), p. 329, Lib. III, Cap. XXX, 9.

${ }^{66}$ SuÁrez (1967), p. 329, Lib. III, Cap. XXX, 9.

${ }^{67}$ SuÁrez (1967), p. 329, Lib. III, Cap. XXX, 9.

${ }^{68}$ SuÁrez (1967), p. 329, Lib. III, Cap. XXX, 9. 


\subsection{Restricción de la defensa por repulsión en Löffler}

Uno de los primeros autores en tratar esta problemática en la dogmática alemana es Löffler ${ }^{69}$. Él delimitó el campo de aplicación de la legítima defensa de casos de defensa por repulsión (Trutzwehr) en los cuales la defensa debería ser menos intensa, porque en la legítima defensa se reacciona contra una agresión ilegítima. Consideración que se ha mantenido sin modificaciones en el plano dogmático y jurídico de los últimos siglos.

En la legítima defensa la víctima no debe retroceder ni un centímetro en el ejercicio de sus derechos. Sin embargo, postula Löffler que podrían darse casos en los que sólo el honor de la víctima se vea amenazado. En esta hipótesis debería ponerse límites a la fuerza, porque es preferible enseñarle una actitud que haga cambiar para bien al agresor. A esto denomina Löffler defensa por repulsión (Trutzwehr).

Asimismo, el honor de la víctima no está en peligro si el atacante es un loco, siendo meritorio si un oficial reduce su ataque con guardias en vez de con su $\operatorname{arma}^{70}$. En el conocido estado de necesidad defensivo no se puede tratar al atacante como a un enemigo, porque es un compañero de derechos. Sólo en el caso en que no haya otra alternativa puedo dañarlo. Sería absurdo matar a alguien sólo para recuperar un botón de mi ropa ${ }^{71}$. Casos que son calificados por Löffler como una legítima defensa en sentido limitado o defensa por repulsión, propios del estado de necesidad defensivo en la actualidad ${ }^{72}$.

Nadie podría considerar el peligro generado por un imprudente, una agresión ilegítima propia de la legítima defensa. Así, el imprudente no puede recibir una respuesta de la entidad de esta última defensa. Por ello, en estas situaciones es plausible preguntarse si es posible al agente evitar de una manera menos perjudicial el peligro de afectar intereses de terceros. De ahí la exigencia de moderación de que no exista otro medio practicable y menos perjudicial para evitar un mal grave en la circunstancia segunda del art. $10 \mathrm{~N}^{\circ} 11$. De lo contrario, podría admitirse matar a un ciclista que pasa por nuestro terreno destruyendo las flores. Nadie puede responder estas preguntas con una respuesta tajante, por

\footnotetext{
${ }^{69}$ LÖFFLER (1901), pp. 542-545.

${ }^{70}$ LÖFFLER (1901), p. 544. En este contexto, la agresión del demente no debe ser tolerada, pero sería deseable reaccionar con más cautela por medio de una defensa por repulsión o estado de necesidad defensivo. Posición que se contrasta con el rechazo de tolerar agresiones de dementes en la dogmática, véase KindHÄUSER (2013), p. 92; OetKer (1908), p. 264.

${ }^{71}$ LÖFFLER (1901), p. 545.

72 Mañalich (2013a), p. 256, nota 181.
} 
lo que no queda otra opción que hacer diferencias dentro de la misma legítima defensa reconociendo la defensa por repulsión ${ }^{73}$.

La moderación es un elemento que denota exigencias en el cumplimento de la cláusula de subsidiariedad del estado de necesidad. Dicho elemento, en realidad, no es más que consecuencia de la aplicación de matices a peligros actuales o inminentes que no pueden ser constitutivos de una agresión ilegítima. La tradición de pensamiento en la que tiene origen la moderación recibe estas limitantes del modo en que las articuló Löffler e incluso otros autores como Soto y Suárez. Pero Löffler no es, ciertamente, el precursor de éstas.

Como se aprecia en el razonamiento que hemos expuesto, la importancia de la defensa por repulsión radica en que el agente afectado, si bien es la fuente de peligro, no es un agresor. Es entonces, inadecuado reaccionar con la misma intensidad que en la legítima defensa, por muy justificado que parezca. Dicho con otras palabras, ningún efecto positivo es suficiente para desconocer en el origen del estado de necesidad defensivo y la importancia de la integridad física del que se ve perjudicado.

Incluso desde la perspectiva de quien se ve afectado por una acción de guerra justificada, se tenía claro en la neoescolástica que "quien resulta dañado como efecto colateral de una acción lícita, no goza del derecho de defensa en el sentido de que le sea lícito 'repeler la fuerza con la fuerza', es decir, no puede usar medios que importen agredir a quien realiza la acción"74. Sin embargo, en la línea de Suárez, los inocentes pueden defenderse de los agentes que justificadamente atacan su ciudad de forma puramente defensiva (pura defensione). Es decir, al impedir que la ciudad se destruya con la finalidad de resguardar su vida. No obstante, no pueden defenderse repeliendo fuerza con fuerza, porque no sufren ninguna ilegalidad ${ }^{75}$.

Debemos considerar que la doctrina, actualmente, desglosa tal constelación de casos a partir del estado de necesidad agresivo que, para sustraerlo de sus límites propios, surgen de la cláusula de ponderación y proporcionalidad. Es decir, precisamente con el objeto de darle al estado de necesidad defensivo un tratamiento más moderado y limitado que en el caso de la legítima defensa.

Sin embargo, estas consideraciones no son suficientes para limitar la aplicación del estado de necesidad defensivo, porque, en la actualidad, ante la indeterminación semántica del concepto peligro, se justifica la muerte de inocentes. Se trata de situaciones asimétricas o simétricas de estado de necesidad

\footnotetext{
${ }^{73}$ LÖFFLER (1901), p. 545.

${ }^{74}$ García-Huidobro y Miranda (2013), p. 368.

${ }^{75}$ SuÁrez (1858), tr. 3, disp. 13, sec. 7, № 19.
} 
en las cuales no es posible atribuir el peligro a los involucrados. No obstante, en orden al concepto de peligro serían aparentemente responsables. Un ejemplo claro es el de dos alpinistas que por una circunstancia extraordinaria quedan colgando en un acantilado unidos por una cuerda y esta comienza lentamente a ceder. En este caso ninguno es responsable de la situación. Ciertamente, que uno de estos "pierda el control del cuerpo [...] debiera llevar a excluir la atribución de una competencia primaria por el peligro" ${ }^{\prime 76}$. Sin embargo, otros observan en esta pérdida de control una fuente de peligro propia del estado de necesidad defensivo ${ }^{77}$.

A continuación explicaremos, en el siguiente apartado, el modo en que las consideraciones de Soto, Suárez y Löffler, entre otros autores, pueden entregarnos luces en torno a la moderación en materia jurídico-penal.

\subsection{Consideraciones en torno a la moderación}

De lo expuesto en esta tercera sección se siguen dos consecuencias significativas para el estado de necesidad. Por una parte, en el estado de necesidad no se trata sólo de la preservación de la vida ante un peligro cierto de muerte, sino de la preservación de un interés jurídico que corresponde al necesitado en razón de la moderación. De lo contrario, no consideraríamos al tercero afectado como un compañero de derechos, en los términos de Löffler. Por otra parte, para el estado de necesidad rige el criterio de la ausencia de moderación cuando no sea posible, ante un peligro cierto de muerte, exigirle al agente ajustar su comportamiento a la regla de conducta. En tal medida, parece del todo posible considerar una sola restricción: la imposibilidad de otro camino o medio para enfrentar el peligro.

Conforme con lo anterior, en la fórmula de ausencia de moderación se ha introducido más de lo que se observa desde una primera lectura: ausencia de toda subsidiariedad. El estado de necesidad requiere de una fuente de peligro de muerte cierta y que no exista otro medio para enfrentar el peligro que matar a otro ser humano inocente. Sin embargo, no se desarrolla con precisión esta funcionalidad de la ausencia de moderación, dentro de una teoría completa del estado de necesidad, centrándonos sólo en reflexionar acerca de la inutilidad de la represión del comportamiento ${ }^{78}$. Posición que resulta incompatible con la posibilidad de considerar otros casos de estado de necesidad defensivos en los

\footnotetext{
${ }^{76}$ Wilendann (2016), p. 34.

${ }_{77}$ Véase Pawlik (2002), pp. 321 y ss.

${ }^{78}$ En este sentido, incluso en el modelo kantiano la exigencia de moderación se invoca en relación con la acción de salvaguarda en el estado de necesidad o de defensa en la legítima defensa, esto es, respecto del sujeto destinatario de la regla. En cambio, lo que conduce a la ausencia de punibilidad en la situación extrema de necesidad, es la falta de efectividad de la pena judicial, por consiguiente,
} 
cuales se debe exigir moderación. Con ello, queda pendiente desarrollar esta ausencia de moderación, en la siguiente sección, en que inevitablemente la única forma de enfrentar un peligro es terminar con la vida de seres humanos inocentes.

\section{Reconocimiento dogmático de la inevitabilidad en el estado de necesidad}

La necesidad inevitable admitida entre los canonistas, en el caso de la legítima defensa, adquiere preponderancia en la noción de estado de necesidad de Jiménez de Asúa, que registra su comienzo en Carrara ${ }^{79}$. La inevitabilidad en Carrara exige tres requisitos presentes en la noción de peligro. El peligro que nos induce a actuar (estado de necesidad) o reaccionar (legítima defensa) debe ser imprevisto, actual y absoluto. La imprevisión apunta a que no podemos ponernos en la situación de matar o ser matados. La actualidad de la agresión debe ser directa, sin tener origen en la venganza por un hecho del pasado. El mal que nos amenaza no puede ser enfrentado de otro modo: la inevitabilidad en sentido absoluto ${ }^{80}$. Si bien reconoce Jiménez de Asúa el origen de la inevitabilidad en este modelo, solo resalta la última característica: el peligro debe ser absoluto. Perspectiva que lo llevó a sostener en el estado de necesidad que "la necesidad puede remediarse de cualquier modo, siempre que no podamos usar otro $^{\prime 81}$. De esta forma, podríamos eximir de responsabilidad a quien, para no morir congelado en un bosque, prende unos árboles ocasionando un incendio ${ }^{82}$.

En esta línea, en la sentencia del Tribunal Supremo Español (en adelante TSE) del 3 de diciembre de 1987, se indica que "la inevitabilidad del mal ocasionado, encarnación del principio de la acción subsidiaria [...] sólo permite actuar cuando el peligro no puede eludirse de otro modo; concepto éste que está en la base misma de la expresión de estado de necesidad acuñada por las reformas penales de 1932 y 1944, en las que tal justificante (o causa de inculpabilidad si el conflicto se agudiza hasta alcanzar a bienes de igual valor) alcanzó toda su extensión, de modo que hay que partir de tal concepto como un prius, anterior, por ende, a los requisitos que lo condicionan y que se enumeran en el precepto (art. $8^{\circ}, 7^{\circ}$ del Código Penal)" $)^{83}$.

no dice relación la moderación con el destinatario de la regla, sino que con la inutilidad de la sanción que puede imponer el juez, véase KANT (1968), pp. 235-236.

${ }^{79}$ Reconoce el origen expreso de esta en la teoría de Carrara en Jiménez de Asúa (1995), p. 206.

${ }^{80}$ CARrara (1988), pp. 209-211, §§ 302-309.

${ }^{81}$ JiMÉNEZ de Asúa (1961), p. 419.

${ }^{82}$ MANZINI (1933), p. 346.

${ }^{83}$ Sentencia del TSE del 8-12-1987 (Ponente: Díaz Palos). Énfasis añadido. En este sentido, reconocen la inevitabilidad de forma expresa en el estado de necesidad, véase JiMÉNEZ DE AsúA (1961), p. 417; 
En esta sentencia existe reconocimiento expreso de la inevitabilidad como base que define la imposibilidad de actuar de otro modo a partir del reconocimiento del estado de necesidad como una colisión de intereses en que para salvar a uno de ellos se precisa el perecimiento o menoscabo de otro u otros. Es el prius o principio lógico del estado de necesidad. Inevitabilidad que se materializaría en una acción subsidiaria conforme a la interpretación del tribunal. Esta lectura de la inevitabilidad se presenta en diversos autores de la doctrina española ${ }^{84}$, pero también en la italiana, alrededor de la década de los ochenta, en lo referente a la imposibilidad de eludir el peligro de otro modo ${ }^{85}$.

Si bien este reconocimiento de la inevitabilidad es consagrado de forma más explícita con la sentencia del 3 de diciembre de 1987, permitió en el pasado al TSE incorporar en el estado de necesidad requisitos adicionales. Así, en un caso de hurto famélico, en sentencia del 8 de junio de 1935, exigió acudir a la beneficencia pública o privada. Razonamiento que responde, como también se da en el caso de la jurisprudencia argentina, según Jiménez de Asúa, a un "afán injustificado de restringir la aplicación del estado de necesidad" ${ }^{\prime 86}$.

EI TSE también sostuvo en la sentencia del 16 de septiembre de 1982 que "los acusados antes de perpetrar un delito contra la propiedad para obtener dinero con el que adquirir la heroína que anhelaban, pudieron y debieron someterse a una cura de deshabituación con la que hubieran logrado calmar sus ansias sin necesidad de atentar contra el patrimonio ajeno" ${ }^{87}$. Por ello, a un drogadicto, bajo un síndrome de abstinencia, se le podría exigir someterse a un control de

\footnotetext{
Morales (2007), p. 516; Morales (2011), p. 224. En el caso de Baldó existe una referencia indirecta al término por medio del concepto de necesidad concreta. Ello, porque trata la inevitabilidad desde su naturaleza operativa haciendo referencia a la cláusula de subsidiariedad. No obstante, enuncia este concepto haciendo referencia expresa a la sentencia del TSE del 3 de diciembre de 1987, que reconoce la inevitabilidad como parte de la esencia del estado de necesidad, véase BALDó (1994), p. 150, nota 334.

${ }^{84}$ El medio seleccionado debe ser el menos lesivo y no lo sería de ser posible la huida, porque la necesidad debe ser absoluta conforme al criterio del TSE en CEREZO (2005), p. 248; ANTÓN (1986), p. 360.

${ }^{85}$ En esta línea, en una comparación entre la legítima defensa (art. 52) y el estado de necesidad (art. 54) del modelo penal italiano se plantea que, desde un punto de vista razonable, el límite de la necesidad-inevitabilidad no puede ser el mismo en estas defensas. Las hipótesis que contemplan son diferentes, porque en el caso del estado de necesidad no estamos ante un agresor pudiendo afectar a un tercero inocente. Por ello, es posible justificar la restricción de un peligro no evitable de otra forma en el art. 54 del CP italiano, véase Grosso (1964), pp. 11-12. El peligro es inevitable cuando no puede escaparse de otro modo que menoscabando el derecho de otros. Por ello, si el agente puede escapar por otros medios, no puede alegar estado de necesidad, véase BatTAGLIANI (1949), p. 334. En esta línea, sustentan una mayor exigencia de la inevitabilidad en el estado de necesidad, ConTIERI (1939), pp. 62 y ss.; Antolisei (1969), p. 238; Molari (1964), pp. 72 y ss.

${ }^{86}$ JIMÉNEZ dE Asúa (1961), p. 418.

${ }^{87}$ Sentencia del TSE de 16 de septiembre de 1982 (Ponente: Vivas Marzal). Énfasis añadido.
} 
impulsos antes de sostener una defensa de estado de necesidad, de sustentar la interpretación del TSE.

En oposición a esta lectura de la necesidad absoluta, como el único medio para enfrentar el peligro, se plantean Córdoba Roda y Rodríguez Mourullo. Según estos autores, el agente que pretende salvar un bien puede ser que no altere el requisito de que el mal causado no sea mayor que el que se trate de evitar de no elegir el medio menos lesivo. Requisito que no comprende una "absoluta necesidad del medio interpuesto, es decir, del mal causado" ${ }^{\prime 88}$. Sin embargo, reconocen estos autores que la posición dominante desprende del requisito en cuestión una calidad absoluta que se traduce en la inexistencia de otro medio para enfrentar el peligro ${ }^{89}$.

\subsection{Grados de intensidad en la inevitabilidad}

El problema de la inevitabilidad no está en su reconocimiento en la necesidad, sino en comprender cuál sería su grado de intensidad dentro de ésta. En otras palabras, cabe preguntarnos: ¿la inevitabilidad debe ser comprendida como parte de la esencia o la naturaleza de la necesidad? De aceptar que funda su esencia: ¿sería plausible exigir un único camino para enfrentar el peligro? La respuesta, ciertamente, incide en el análisis de la concurrencia de la eximente o una incompleta en defensa del agente ${ }^{90}$. Esta relación dogmática de la inevitabilidad con una necesidad absoluta -como hemos dado a conocer- nace del reconocimiento del modelo de Carrara en la dogmática italiana, española y, principalmente, del razonamiento de la jurisprudencia del TSE. La inevitabilidad relacionada con la selección del medio permite a la dogmática sostener su materialización en el requisito de subsidiariedad ${ }^{91}$.

Sin embargo, esta compresión de la inevitabilidad absoluta será discutida, en torno a la interpretación del requisito de subsidiariedad, por un sector importante de la doctrina española más reciente. Así, un grupo sustenta que ante una conducta relevante, en términos de tipicidad, el no seleccionar el medio menos lesivo no afecta la concurrencia de una eximente incompleta del estado

\footnotetext{
${ }^{88}$ Córdoba y Rodríguez (1972), p. 278.

${ }^{89}$ Córdoba y RodríGuez (1972), p. 278; Valle (1992), pp. 588-589. En esta línea, es importante destacar que se desprende esta posición dominante de la doctrina italiana, véase CóRDOBa y RodRíGuEz (1972), p. 278, nota 19.

${ }^{90}$ Para que estemos en presencia de una eximente incompleta "nunca ha de estar ausente el elemento esencial o base, por ejemplo, la agresión ilegítima en la legítima defensa", Vargas (2011), p. 212.

${ }^{91}$ Sostiene esta posición de forma expresa en la dogmática española Morales (2007), p. 516. De forma tácita en el modelo español, BALDó (1994), p. 150; VALLE (1992), pp. 588-589. En la dogmática nacional, Cousiño (1979), p. 400.
} 
de necesidad ${ }^{92}$. La selección de los medios debe estimarse desde una necesidad concreta, es decir, no absoluta ${ }^{93}$.

Conforme con lo anterior, la esencia del estado de necesidad se correlaciona con una necesidad abstracta que responde a una situación de peligro actual o inminente del que sólo puede escaparse causando otro mal ${ }^{94}$. Situación en la que inevitablemente se debe generar un mal, pero la selección de la entidad de este mal no es parte de la esencia de la necesidad. El modelo chileno extrae la inevitabilidad -en el caso del art. $10 \mathrm{~N}^{\circ} 7$ - del CP español de 1848, que disponía que no haya otro medio practicable, y menos perjudicial, para impedirlo. Cláusula que subsiste en el CP español de 1870 y reaparece en los de 1932 y $1944^{95}$. Sin embargo, en el presente, el art. 20.5 del CP español prescinde de esta exigencia porque, inexcusablemente, parece entenderlo sobrentendido en la necesidad ${ }^{96}$. No obstante, permanece el requisito en nuestro ordenamiento, en la circunstancia segunda del art. $10 \mathrm{~N}^{\circ}$ 11: Que no exista otro medio practicable y menos perjudicial para evitarlo.

De considerar la inevitabilidad como la lógica rectora del estado de necesidad del art. $10 \mathrm{~N}^{\circ} 11$, en la línea de la sentencia del 3 de diciembre de 1987 del TSE, siempre sería viable, hipotéticamente, buscar medios menos perniciosos

92 Valle (1992), pp. 589-590; Córdoba y Rodríguez (1972), p. 278; Mir (2011), p. 473; Paredes (1989), p. 125; Baldó (1994), p. 156; Morales (2011), pp. 224-225. En este contexto, debemos agregar que algunos comparten la opinión de que este problema se genera por una confusión conceptual entre el criterio que mide la necesidad y la selección del medio menos gravoso, véase VAlLE (1992), p. 590; Morales (2011), p. 224; Cuerda (1996), p. 149.

${ }^{93}$ En la dogmática penal italiana se puede observar que se adhiere a esta consigna en CADOPPI Y VENEZIANI (2007), p. 252. Sin embargo, la inevitabilidad expresamente consagrada en el art. 54 del modelo italiano, relativa al estado de necesidad, pretende hacer énfasis en que la conducta incriminada debe ser realizada con el menor daño posible, porque puede involucrar la afectación de los derechos de un tercero inocente. Inevitabilidad que no se encontraría presente en el art. 52 de la legítima defensa, pero sí en el 54 del estado de necesidad, DonAto (2007), p. 159. El art. 54 requiere que la comisión de un hecho penalmente relevante sea necesaria para la protección de un peligro grave en la persona o de un tercero. Ello implica la ausencia de un medio menos lesivo o alternativa igualmente eficaz para neutralizar el peligro. Razonamiento que parece tener un cierto parangón con la legítima defensa aunque más exigente en el estado de necesidad. Ello, cuando no sea posible una salida del agredido que implique un riesgo para su integridad física, MarinuCCI y DolCinI (2006), pp. 227-228; PaGliaro (2003), p. 448; Garofol (2008), pp. 504-505. Por su parte, observa Padovani en la frase "non altrimenti evitabile" la exigencia de que la situación de peligro no haya sido provocada por el necesitado, Padovani (2006), p. 241.

${ }^{94} \mathrm{Si}$ bien se sostiene que el peligro es un presupuesto necesario para el estado de necesidad, este se encuentra condicionado por la existencia del concepto de necesidad, BALDó (1994), pp. 147 y ss.

95 Cousiño (1979), p. 400; JiméneZ de AsúA (1961), p. 417.

${ }^{96}$ Exigen antecedentes de la idea de prescindir de la subsidiariedad en el estado de necesidad, al ser parte la inevitabilidad de la necesidad, considerando que los Códigos Penales de 1848, 1870, 1932 y 1944 en España la mantuvieron, en JiméneZ de Asúa (1961), p. 417. 
para enfrentar el peligro. Una interpretación de este tipo limitaría en exceso la aplicación de la eximente; la haría impracticable. Así, de no seleccionar el agente el medio menos dañoso para enfrentar el peligro, no existiría estado de necesidad ${ }^{97}$. Pero el art. $10 \mathrm{~N}^{\circ} 11$ se diferencia de regulaciones como las del $\S 54$ del CP alemán de 1871, que eximen de responsabilidad al agente que actúa ante un peligro de otro modo insuperable (auf andere Weise nicht Uwseitigenden). Estándar que presenta semejanza con los $\S 34$ y $\$ 35$ del actual CP alemán, al indicar que el agente actúe ante un peligro no evitable de otro modo (nicht anders abwendbaren Gefahr ${ }^{98}$.

No obstante lo anterior, el modelo chileno indica que no exista otro medio practicable y menos perjudicial para evitarlo. Exigencia que solicita comparar los medios en concreto de los cuales dispone el agente para afrontar la situación de peligro. Así, la idoneidad se manifiesta como un examen concreto de los medios que se disponen. En cambio, la expresión no evitable de otro modo es más limitada, porque nos conduce a la exigencia de la selección de un único medio. Así las cosas, Rivacoba, antes de la regulación presente en el art. $10 \mathrm{~N}^{\circ} 11$, aseveró que la necesidad, en el caso de la legítima defensa, contempla la inevitabilidad ${ }^{99}$ y Cousiño rechazó la idea de que la inevitabilidad sea la esencia del estado de necesidad, porque sólo es una exigencia propia de su naturaleza ${ }^{100}$. Por su parte, Fuentes añadió en la doctrina chilena, que

\footnotetext{
${ }^{97}$ Este requisito tiene por propósito delimitar la aplicación del estado de necesidad, al establecer que no exista otro medio practicable y menos perjudicial para evitar el mal. Se debe atender a las posibilidades concretas del sujeto que actúa y no a las simplemente teóricas, con el objeto de no llegar al extremo de nunca aplicar la eximente. Por ello, aparentemente, la subsidiariedad es parte esencial del estado de necesidad, porque constituye un filtro, frente a la existencia de un peligro inminente, para aplicar esta eximente, Politoff et al. (2003), pp. 231-232; NÁQuira (1998), p. 259; Couso (2011b), p. 237; FueNTES (2009), p. 27; CURY (2005), pp. 380-381, entre otros.

${ }^{98}$ En la dogmática alemana, Lenckner indica que la regulación del § 34 del StGB es desacertada e infeliz como la línea jurisprudencial que exige un único camino para evitar el peligro, LENCKNER (1998), p. 499. Sobre este mismo punto en la doctrina española, en atención a la necesidad absoluta, MIR (2011), p. 473; BALDó (1994), p. 148. Sobre esta materia, específicamente, respecto del § 54, véase Cousiño (1979), p. 401.

${ }^{99}$ Rivacoba y Rivacoba (1965), p. 266.

${ }^{100}$ Cousiño (1979), p. 400. Nos parece que las raíces de esta necesidad concreta de la dogmática nacional se observan en Cousiño. Sostuvo que la esencia de la necesidad se vincula de forma expresa con la noción de peligro y no con una restricción de los medios utilizados por el agente. Consideró que, en atención a la regulación del art. $10 \mathrm{~N}^{0} 7$, la subsidiariedad es sólo un requisito propio de la naturaleza del estado de necesidad. La subsidiariedad carecería de autonomía en la aplicación de la eximente. Como consecuencia, el necesitado, antes de la ejecución de la acción, estará obligado a acudir al medio menos lesivo que se encuentre a su disposición y no únicamente a un solo medio. Así, el agente amenazado por un animal doméstico deberá intentar escapar antes que matarlo; el bañista privado de su vestimenta deberá optar por esconderse en la oscuridad antes que hurtar la ropa de un tercero; el hambriento deberá
} 
la subsidiariedad, sin aludir a la inevitabilidad, sería la exigencia que "de manera más propia nos habla de la necesidad"101. La única posición que rescata directamente a la inevitabilidad de la noción de necesidad es la de Rivacoba. Pero la presenta en la legítima defensa en una perspectiva concreta, porque la necesidad abstracta procede, únicamente, de una agresión antijurídica. Así, ninguno de los mencionados autores considera la inevitabilidad en una línea abstracta o absoluta ${ }^{102}$.

De ahí que sea necesario preguntarse: si la inevitabilidad es parte del estado de necesidad y tiene una calidad absoluta en la selección del medio menos lesivo. Pues bien, en atención a los casos más extremos del estado de necesidad, como el de los dos náufragos que pelean por una tabla para no morir ahogados; el del tren que pierde el control pudiendo ser desviado a una pista en la que mueran menos personas, entre otros, podemos percatarnos que comparten en común que, tratándose del sacrificio de la vida de un inocente, se exige que no exista otro medio menos perjudicial ${ }^{103}$.

\subsection{Inevitabilidad absoluta}

Dejando de lado estos casos de laboratorio (Lehrbuchkriminalität) ${ }^{104}$, por su compleja ocurrencia en la realidad, debemos determinar qué sucedería en

recurrir a la compasión de otros antes que hurtar comida. Sin embargo, esto no implica considerar la inevitabilidad en un sentido abstracto; es decir, que la inevitabilidad no responde a un único camino, sino más bien a la selección del medio menos lesivo para enfrentar el peligro. En esta línea, Cousiño afirmó que, "como ocurre en nuestro Código Penal, la practicabilidad de otro medio menos perjudicial no puede establecerse conforme a reglas o cánones absolutos y, de todos modos, es un juicio ex ante, aunque deba comprobarse ex post facto", Cousiño (1979), p. 401. En este plano, en la doctrina nacional sustentó que el "peligro [...] condiciona la necesidad, hasta el punto de constituir su núcleo esencial", en CousiÑo (1979), p. 372. Posición que sostiene en la dogmática nacional también en ETCHEBERRY (1998a), p. 262; Politoff et al. (2003), p. 228; GarRido (2007b), p. 183, entre otros.

101 Fuentes (2009), p. 27.

102 Rivacoba y Rivacoba (1965), p. 267. Así, "siendo esta inevitabilidad [...] uno de los aspectos del carácter necesario de la defensa, tiene que ir matizada por el adjetivo que la califica: racional; de manera que no ha de entenderse en términos absolutos, sino -porque luego veremos- relativos a las circunstancias de cada caso objetivamente o en sí mismas consideradas [...]", Rivacoba y Rivacoba (1965), p. 267.

${ }^{103}$ En la lista de casos extremos de necesidad podemos agregar el del avión con pasajeros inocentes conducido por un terrorista con el propósito de estrellarlo contra un edificio; el caso de aquel que puede desviar el vehículo de un conductor imprudente disparándole en la rueda para que no lo mate; el del alpinista que debe cortar la cuerda para no caer con su compañero al precipicio; el utilizar como escudo humano a una persona para protegerse de las balas que dispara un tercero; la coacción que ejerce una banda terrorista para que el agente cometa un delito de incendio, homicidio o mutilación sobre su persona o de terceros relacionados; el caso de quien apunta con una pistola a otro para que viole o mate a una persona, etc.

104 SiLVA (1998a), p. 37. 
situaciones en las cuales se acepte el sacrificio de vidas humanas sin estar en presenciar una inevitabilidad absoluta. De esta forma, a modo de ejemplo, es significativo el caso de aborto terapéutico, respecto de una mujer que presentaba una depresión reactiva, que dio lugar a un estado de necesidad supralegal en la sentencia del Reichsgericht de 11 de marzo de 1927 (RGSt 63, 211). En este caso, la mujer tuvo relaciones sexuales con un turista mientras se encontraba sometida a un tratamiento neurológico por trastornos nerviosos. Al mencionarle la probabilidad de que estuviera embarazada, corroborada por los resultados del examen ginecológico, se descontroló emocionalmente revelando tendencias suicidas. El neurólogo prescribió que existía un peligro real de suicidio en la mujer como resultado de una depresión reactiva generada por el embarazo. Por ello, convenció a su médico ginecólogo que le practicara un aborto para terminar con el peligro de suicidio de la paciente ${ }^{105}$.

Sin embargo, en el caso en cuestión resulta posible asumir el peligro de suicidio de la paciente, a través de un tratamiento psiquiátrico o control clínico permanente en su embarazo. La muerte del no nacido no es el único medio para enfrentar el peligro. Así pues, matar al no nacido en una situación de estado de necesidad no transforma en lícito lo ilícito. De lo contrario, daríamos una "flexibilización amplia [a] situaciones de necesidad para la admisión de un aborto no punible ${ }^{\prime 106}$ que atentaría contra la dignidad humana, porque la fuente de peligro sería la enfermedad mental de la mujer y no la existencia del feto ${ }^{107}$.

Otro célebre caso es el de la sentencia del Oberster Gerichtshof für die Britische Zone (Tribunal Superior de Justicia para la Zona Británica) de 5 de marzo de 1949 (OGHSt 19-49) ${ }^{108}$. En este, Hitler decretó, el 2 de septiembre de 1939, una orden requiriendo de los establecimientos psiquiátricos información sobre la capacidad de trabajo de estos pacientes y las características de sus enfermedades mentales. Con esta información se crearon listas de personas que habrían de ser reubicadas en establecimientos donde se les daría muerte. En 1941 el Ministerio de Interior consintió, antes de que se diera inicio a estos traslados, excluir de las listas a ciertos pacientes.

Los psiquiatras acusados fueron miembros de la comisión que se encargaba de examinar las listas en cuestión. En tal revisión se enfocaron por borrar a todos los pacientes que fuera viable, con insubordinación a las directrices del régimen

\footnotetext{
105 Más información en torno a los presupuestos del caso y análisis de los hechos en PeRCY (2011), pp. 129-144.

106 PerCy (2011), p. 141

107 Ossandón (2012), pp. 345, nota 91, y 344; Silva Sánchez (2007), p. 14.

108 Para un detalle pormenorizado de los hechos y su análisis completo, véase ORTIZ DE URBINA (2011), pp. 177-192.
} 
y triunfo en diversos casos. El jurado consideró que los psiquiatras procedieron en un estado de necesidad supralegal justificante. Decisión que fue recurrida por el fiscal, negando la sala penal del Tribunal Superior de Justicia para la Zona Británica, la existencia de este estado de necesidad. Los acusados fueron absueltos por una causal personal de exclusión de la pena.

El mal causado en este caso es participar en la elaboración de una lista que tiene por objeto una política eugenésica. En cambio, el mal evitado es salvar de estas listas a diferentes pacientes, contra las órdenes expresas del régimen nazi. En este caso, ciertamente, no existe otro medio para salvar a estos pacientes que eliminar de la lista a los enfermos que se pueda ${ }^{109}$. Además, el medio del tiranicidio de Hitler nos parece una exigencia desproporcionada para estos dos psiquiatras, porque los transformaría en mártires de una causa que tendría por consecuencia su muerte. Efectivamente, estos evitaron con su comportamiento que un número mayor de pacientes muriera.

Urbina sostiene que, en el caso de estos psiquiatras, estamos en un conflicto de vidas que están destinadas a extinguirse por una orden fuera de su control. La decisión de intervenir en dicho curso causal, para salvar la mayor cantidad de pacientes, supone un mal menor que omitir participar. La omisión de estos hubiera conllevado la muerte de todos o de la inmensa mayoría de los pacientes. En esta situación, según Urbina, se opta por el mal menor, decisión que puede acogerse en un estado de necesidad justificante ${ }^{110}$. Sin embargo, consideramos que la acción no puede tener semejante tratamiento, porque la orden que determinó el destino de estos pacientes no transforma en lícito lo ilícito de la acción de los psiquiatras ${ }^{111}$.

El hecho de incidir en el curso causal de la decisión, ponderando las consecuencias de la intervención, no justifica determinar quién vive o quién muere ${ }^{112}$. Nos parece que el núcleo esencial de la dignidad humana no es ponderable, porque la sociedad no está preparada para enfrentar la tarea de establecer

\footnotetext{
109 Sin embargo, debemos considerar que en el caso en cuestión algunos sostienen que la consecuencia de incumplir las órdenes de Hitler era sólo que los psiquiatras fueran despidos o afectado en su remuneración.

${ }^{110}$ Ortiz de URBINA (2011), p. 192.

111 Ortiz de Urbina (2011), p. 192.

112 En casos de dudas entre la ponderación de principios debemos siempre recordar que las metarreglas provocan que la "argumentación jurídica en general [...] se mueva más en defensa de la dignidad, luego en defensa de la libertad, y luego en la defensa de la socialidad", SánCHez-Ostız (2012b), p. 81.
} 
criterios objetivos para medir el valor de las vidas humanas ${ }^{113}$, implicaría "abrir una caja de Pandora que es preferible mantener cerrada"114.

En casos como los enunciados, nos parece que se han cometido graves atentados contra el núcleo de la dignidad humana. Ciertamente, en el primero (aborto terapéutico) se olvidó por completo la inevitabilidad, porque no se consideró la posibilidad de un tratamiento psiquiátrico de la gestante o la vigilancia clínica permanente durante su embarazo. En el segundo (psiquiatras en el régimen nazi), si bien es cierto que no existe otro medio para salvar la vida de algunos de los pacientes, nos parece que la decisión de intervención de los psiquiatras afecta de todas formas el núcleo esencial de la dignidad humana, por la sencilla razón de que nunca es lícito matar a un ser humano inocente, aunque las consecuencias o el saldo sean positivos, porque es abrir una ventana donde puede ser posible la justificación de cualquier decisión.

Así, la inevitabilidad -como hemos podido contemplar-adquiere un rol fundamental, porque la ponderación de males puede transformarse en una herramienta perversa cuando no se considera la existencia de prohibiciones deónticas que impidan matar a seres humanos inocentes o un núcleo esencial de la dignidad humana no susceptible de ponderación. El hecho de comprobar la existencia de un único medio de enfrentar el peligro, sacrificando vidas humanas o afectando su integridad física, no libera al agente de la carga de por qué ésta fue su única alternativa, centrando esta pregunta en el ámbito de la exculpación.

Estos dos casos nos permiten ilustrar que no se puede prescindir de la inevitabilidad y que resulta especialmente importante cuando se afecta la vida de inocentes, con independencia de los efectos del estado de necesidad. El caso del aborto terapéutico no puede comprenderse dentro del estado de necesidad porque existen otros medios menos lesivos para enfrentar el peligro, y el de los dos médicos psiquiatras, aunque con dificultades, puede ser parte del mismo debido a que no existe otro camino, la inevitabilidad de su conducta. Exigir un comportamiento heroico a los psiquiatras en oposición al régimen acarrearía una muerte segura.

\footnotetext{
${ }^{113}$ En el plano del terrorismo debemos destacar que "parece demasiado simple descartar (con base en un absoluto y estricto punto de vista deontológico de moralidad) cualquier intento de balance respecto de la prohibición absoluta de la tortura y de la implícita violación de la dignidad humana, es igualmente poco convincente una ponderación aislada meramente cuantitativa que haga un balance entre la persona secuestrada y las víctimas potenciales de un ataque terrorista por un lado, y la víctima de tortura por otro", Amвоs (2009), p. 59. Ello, considerando la prohibición absoluta de tortura en el plano internacional.
}

${ }^{114}$ CHIESA (2011), p. 104. 


\subsection{Antecedentes de la inevitabilidad en Chile}

Centrándonos en la jurisprudencia nacional podemos encontrar antecedentes de la inevitabilidad en la sentencia de la Corte de Apelaciones de Chillán de 1954, que absolvió a una mujer que dio muerte a su marido maltratador mientras dormía. Precisamente, relacionado con el primer caso en que se aplicó el estado de necesidad del art. $10 \mathrm{~N}^{\circ}$ 11. La sentencia indicó que "no cabe duda de que [la mujer] fue presa del miedo, miedo que, atendida la certidumbre que [...] tenía de su muerte, es insuperable porque concurren en él los requisitos de la inminencia, gravedad, injusticia e inevitabilidad, estados de conmoción violenta que fue provocada por un acontecimiento externo dependiente de los hechos de un tercero, que le produjeron el raptus emocional [...]"115.

$\mathrm{Si}$ bien habla la sentencia del miedo insuperable, destaca exigencias que no son propias del miedo insuperable y sí del estado de necesidad ${ }^{116}$. Reconociendo elementos como la inminencia, gravedad e injusticia del mal que se pretende enfrentar, introduce la inevitabilidad, seguramente, en el miedo insuperable por la ausencia del art. $10 \mathrm{~N}^{\circ} 11$. Este fallo es característico no sólo del problema de interferencia existente entre el miedo insuperable y el estado de necesidad, sino también de la exigencia de la inevitabilidad en el estado de necesidad, esto es, como una necesidad absoluta en la selección de los medios, la cual no esté omitida en situaciones en las cuales se tome la decisión de terminar con la vida de un potencial agresor.

También retornando al primer caso en que se absolvió a un imputado con el art. $10 \mathrm{~N}^{\circ} 11$ (caso de Karina Sepúlveda), podemos darnos cuenta de que la inevitabilidad, en el caso de un tirano familiar, ha sido central. En este caso, el Sexto Tribunal Oral de Puente Alto determinó que la imputada "al momento de actuar lo hizo con conciencia y determinación de que no tenía otra alternativa para evitar su muerte y la de sus hijos más que la de matar; como ya se dijo no

\footnotetext{
115 Sentencia de la Corte de Apelaciones de Chillán de 10-05-1954, Revista de Derecho y Jurisprudencia, t. LII, No s. 9 y 10, 1955, secc. cuarta, p. 211. Énfasis añadido. El mismo fallo se puede observar citado en Alonso (1985), pp. 65 y 66 y en Celis (2001), p. 46 y ss.; Villegas (2010), p. 167. Otros fallos que reconocen en el miedo insuperable el requisito de un mal real, grave e inminente: sentencia Corte de Apelaciones de San Miguel de 24-04-1994, rol № 142-94; sentencia del Tribunal Oral en lo Penal de San Antonio de 22 de julio de 2008, RIT 49-2008, RUC 0700509932-8. En contra de este criterio, VILLEGAS (2010), p. 170.

116 En el caso en comento no se acreditó, conforme a las reglas de la ciencia, la perturbación anímica de la víctima del agente. Más bien se trata de exculpar el comportamiento del agente aludiendo a la situación de peligro que enfrenta y no a un sustrato psicológico con corroboración científica.
} 
era viable denunciar, tampoco ir a una casa de acogida ni recurrir a su familia $[\ldots]^{\prime \prime 117}$.

Así pues, la selección del medio practicable debe ser la única posible, tratándose del sacrificio de vidas humanas o la integridad física de las personas. El núcleo esencial de la dignidad humana no se puede poner en riesgo sin fundamentos de peso ${ }^{118}$. Por ello, para tener resultados adecuados que no lo afecten, debemos contar con un criterio que difiera del resto de los casos de estado de necesidad. En estos casos nos parece que la moderación (moderamen) abandona a la tutela inculpada (inculpatae tutelae) a cambio de la exigencia de un solo medio. El único medio que permite exculpar el comportamiento del agente en este caso, al tener limitante en la ponderación el respeto a la dignidad.

Nos parece que sólo puede prescindir de la selección del medio menos lesivo, para evitar un mal grave, a cambio de una necesidad absoluta en caso de sacrificar una vida humana o la integridad física de una persona. Por ello, consideramos que la mantención de la subsidiariedad en el art. $10 \mathrm{~N}^{\circ} 11$ nos recuerda dos posibilidades de interpretación, a saber: que no exista otro medio practicable u otro medio practicable y menos lesivo que el utilizado por el agente. De ahí que rescatar la primera interpretación sea fundamental en el caso de sacrificar una vida humana o afectar su integridad física. En otras palabras, se rescata la inevitabilidad en sus términos absolutos únicamente en estas situaciones. Se podría anteponer como crítica que siempre pueden existir medios alternativos o menos lesivos para enfrentar el peligro. Identificar la esencia del estado de necesidad con la inevitabilidad plena restringiría en exceso la aplicación de esta eximente; sin embargo, esta restricción nos parece adecuada, en atención a los graves atentados que se podrían cometer en contra de la dignidad humana.

Naturalmente, el art. $10 \mathrm{~N}^{\circ} 11$ recibe influencia del art. 54 del CP italiano, como consta en los Informes de la Comisión Mixta ${ }^{119}$. Dando por supuesto que este último modelo consagra expresamente la inevitabilidad en el inciso primero de su art. $54^{120}$, la expresión nè altrimenti evitabile (no evitable de otro modo)

\footnotetext{
117 Sentencia del Sexto Tribunal Oral en lo Penal de Puente Alto, de 21 de junio de 2013, RUC № 1.101.060.685-5, considerando décimo segundo. Énfasis añadido.

${ }^{118}$ En este contexto, una de las críticas a la incorporación del art. 10 № 11 fue la del senador Chadwick. Objetó que la disposición podía abrir una puerta a las mujeres para actuar sin mesura ante cualquier maltrato. No obstante, el senador Larraín consideró que el requisito de subsidiariedad y gravedad sería la limitante en estas defensas. Llegándose a la convicción de que en estos casos no se exculpa la conducta de existir otro medio para confrontar el peligro, véase BibloteCA del Congreso Nacional (2010), p. 453.

119 Historia de la Ley № 20.480 (2010), p. 249.

${ }^{120} \mathrm{El}$ art. 54 dispone: Non è punibile chi ha commesso il fatto per esservi stato costretto dalla necessità di salvare sè o altri dal pericolo attuale di un danno grave alla persona, pericolo da lui non volontariamente causato, nè altrimenti evitabile, sempre che il fatto sia proporzionato al pericolo, SESSANO (2002), p. 14.
} 
en este destaca una exigencia más rigurosa en la selección del medio menos lesivo que diferiría de la legítima defensa, porque en el estado de necesidad se podría afectar o terminar con los derechos o incluso la vida de terceros inocentes.

Ahora bien, no podemos dejar de reconocer que Cury también adoptó en su propuesta final el modelo suizo ${ }^{121}$. Antecedente importante para comprender el origen, esencia y naturaleza del art. $10 \mathrm{~N}^{\circ} 11$. Sin embargo, éste recurre a autores como Freudenthal y Stooss con el propósito de entender-desde una perspectiva teleológica- cómo se estructura esta disposición desde la inevitabilidad. Respecto de la definición del estado de necesidad recalcó, siguiendo los planteamientos de Freudenthal, que la disposición del art. 10 № 11 es la más adecuada para resolver los conflictos que pueda suscitar una situación de necesidad $^{122}$.

Así las cosas, no está de más indicar que Freudenthal consideró la formulación suiza como una de las más prudentes, "puesto que en ella introduce en el tipo el peligro inminente y no evitable de otro modo, como barrera contra la autoayuda superflua. Por otra parte, el círculo de los sujetos y bienes aptos para el estado de necesidad carece de restricciones, merced a la frase 'un bien suyo o de otro'..., etc. Por lo mismo, la definición es muy cautelosa y lo suficientemente amplia, ambas cosas a la vez"123. Esta formulación, que incide teleológicamente en la creación del art. 10 № 11, incorpora la inevitabilidad en el estado de necesidad.

Es presupuesto evidente que Cury, siguiendo los postulados de Freudenthal, vincula la existencia actual o inminente del peligro a la inevitabilidad ¿Pero por qué la regulación del art. 10 № 11 no incorporó la frase no evitable de otro modo como lo dispone el modelo del CP suizo (nicht anders abwendbaren) o italiano (nè altrimenti evitabile)? La disposición en cuestión continúa con la cláusula de subsidiariedad del art. $10 \mathrm{~N}^{\circ} 7$ (que no haya otro medio practicable y menos perjudicial para impedirlo), cambiando la palabra impedirlo por evitarlo y sustituyendo la palabra haya por exista. Por cierto, la cláusula quedó

¿Énfasis añadido?

\footnotetext{
121 Santibáñez y Vargas (2011), p. 197; Sepúlveda (2012), p. 177; Ossandón (2012), p. 339; Acosta (2013), p. 696. No obstante, no se hace referencia a la importancia que le asignó Cury al modelo suizo en Hernández (2011b), p. 268. Específicamente, Cury adoptó el art. 34 del CP suizo de 21 de diciembre de 1937, modificado el 5 de octubre de 1950, subtitulado Estado de Necesidad, véase CURY (2013), pp. 249-252, 254-255 y 257. Cabe recordar que la introducción de esta disposición en nuestro ordenamiento se recoge de la propuesta de CURY por los parlamentarios, véase BIBLIOTECA del Congreso Nacional (2010), pp. 449 y 453; Santibáñez y Vargas (2011), p. 197. Por su parte, Cury en una de sus últimas clases adujo que el modelo alemán es sumamente mezquino y complicado, por lo que consideró el suizo para la elaboración de la norma, véase CURY (2011); CuRY (2013), p. 257.

${ }^{122}$ CuRY (2013), p. 257.

${ }^{123}$ Freudenthal (2006), p. 97. Énfasis añadido.
} 
formulada en los siguientes términos: que no exista otro medio practicable y menos perjudicial para evitarlo.

A la vista de lo expuesto, la propuesta de Cury nos parece que tuvo por finalidad no perturbar la compresión que la judicatura tiene del estado de necesidad, manteniendo las precisiones a las cuales está habituada, considerando las contribuciones del modelo suizo e italiano ${ }^{124}$. Sin embargo, nos parece que sólo tendría sentido mantenerla de aceptar la dualidad interpretativa a la que recientemente hicimos alusión: que el peligro no pueda evitarse de otro modo (esencia) o por otro medio menos lesivo que el utilizado por el agente, consideración esta última que parece aludir a la naturaleza de la disposición por la idea de ponderación de intereses.

Desechar la cláusula de subsidiariedad como lo hizo el modelo español en su art. 20.5, nos podría llevar sólo a un análisis concreto de los medios en la selección de éstos. Por ello, en consonancia con la dualidad de la cláusula de subsidiariedad, nos parece que la primera línea de interpretación (que el peligro no pueda evitarse de otro modo) se sustenta en casos como los que tenía presentes Stooss en la formulación de la regulación del estado de necesidad suizo que aludían, principalmente, a casos de estado de necesidad exculpante.

Efectivamente, Stooss, en este orden de ideas, consideró al alpinista que debe cortar la cuerda para no caer en un principio con su compañero; el utilizar a alguien como un escudo humano para no recibir las balas que dispara un tercero; aquel que para prestar auxilio a un enfermo grave (en el compartimiento de un tren) debe golpear a quien le impide el acceso por seguridad o el caso de la madre en un naufragio que empuja a uno de los pasajeros del bote de rescate para salvar a su hijo. Casos en los cuales se termina irremediablemente con la vida de un inocente o se afecta su integridad física ${ }^{125}$ y que tuvo en consideración al momento de elaborar la disposición del segundo proyecto del CP suizo de 1899 al incorporar la frase no evitable de otro modo (nicht anders abwendbaren) $)^{126}$.

Es así que la interpretación de la inevitabilidad se torna fundamental para definir si la acción de un agente puede estar dentro de los parámetros del estado

\footnotetext{
${ }^{124}$ CURY (2011).

${ }^{125}$ En otras palabras, la exigencia de la imposibilidad de evitar el peligro de otra manera proviene de las hipótesis más extremas de estado de necesidad. Para Stooss, era un punto crítico si el agente prefirió ponerse sólo en una posición ventajosa sin certeza del acontecimiento del peligro. Mientras más probable sea la materialización del peligro, más fuerte será la razón del agente para salvarse o a un tercero, Stooss (1913), pр. 137-138.
}

${ }^{126}$ Véase Stooss (1899), pp. 43-46. 
de necesidad del art. $10 \mathrm{~N}^{\circ} 11$, en casos en que se afecte el núcleo esencial de la dignidad humana. Estos son los únicos supuestos en los cuales la moderación puede dejar de operar, porque existe un peligro cierto de muerte donde la sanción no tendría sentido. En situaciones extremas de necesidad, se infringe la prohibición deóntica de que nunca es lícito matar a un ser humano inocente ${ }^{127}$, ante situaciones de peligro en que los números cuentan. Sin embargo, esta ponderación debe ser realizada porque no existe otra alternativa.

Por último, consideramos que no es posible establecer una regla general en estas situaciones de vida o muerte. La multiplicidad de variantes del estado de necesidad nos presenta un modelo caótico que no se restringe a una sola modalidad. Sin embargo, sí se puede establecer una limite general en el sacrificio de vidas humanas; esto es, que no exista otro medio. El estado de necesidad es un conflicto de intereses de inevitabilidad graduable donde la ausencia de moderación envuelve su preponderancia plena. Por ello, la distinción de los efectos pende de una ponderación de intereses que tiene por limitante la dignidad humana.

\section{Conclusiones y balance}

La inevitabilidad nace del análisis de la noción de necesidad en la legítima defensa, incorporándose, en el Derecho penal canónico, mediante la distinción entre necesidad evitable e inevitable. Si bien esta exigencia comienza a ser abandonada, en el Derecho penal canónico, a propósito de la legítima defensa de terceros, subsiste en la subsidiariedad en el caso del estado de necesidad. Así las cosas, el estado de necesidad presenta un conflicto de intereses de inevitabilidad graduable donde la ausencia de moderación implica la preponderancia plena de ésta, en casos en los cuales se sacrifique o afecte la integridad física de las personas.

Por tanto, existirían dos líneas de interpretación de la inevitabilidad, consagradas en la cláusula de subsidiariedad del art. 10 № 11, que dispone que no exista otro medio practicable y menos perjudicial para evitarlo. La primera es que no exista otro medio practicable, propio de una inevitabilidad absoluta, restringiendo la aplicación de la eximente a la selección del medio menos lesivo, en casos en los cuales no se pueda exigir moderación. La segunda se desprende de la expresión menos perjudicial para evitarlo, que da lugar al requisito de idoneidad en un sentido concreto; esto es, que la selección del medio sea la menos lesiva, según la situación fáctica de peligro que se pretende evitar.

127 WILENMANN (2016). 


\section{BiBLIOGRAFÍA CITADA}

Acosta Sánchez, Juan Domingo (2013): "Artículo 10 № s. $7^{\circ}$ y $11^{\circ}$ del Código Penal. Algunos criterios de delimitación", en: Van Weezel, Alex (ed.), Humanizar y renovar el Derecho penal. Estudios en memoria de Enrique Cury (Santiago, LegalPublishing), pp. 691-714.

Alonso Arias P., Antonio (1985): El miedo insuperable y la fuerza o violencia moral e irresistible (Santiago, Editorial Conosur).

Амвоs, Kai (2009): Terrorismo, tortura y Derecho penal. Respuestas en situaciones de emergencia (Barcelona, Atelier).

Antón OnECA, José (1986): Derecho penal, $2^{a}$ edición, (Madrid, Editorial Akal).

Antolisel, Francesco (1969): Manuale di diritto penale. Parte generale (Milano, A. Giuffrè).

Baldó Lavilla, Francisco (1994): Estado de necesidad y legítima defensa: Un estudio sobre las "situaciones de necesidad" de las que derivan facultades y deberes de salvaguarda (Barcelona, Bosch).

BANFi Del Río, Cristián (2015): "El principio del doble efecto y la responsabilidad civil", en: Guzmán Brito, Alejandro (ed.), Estudios de Derecho Civil X (Santiago, Editorial Thomson Reuters), pp. 793-810.

BARRIENTOS, Javier (1998): "El pensamiento económico en la perspectiva filosóficoteológica", en: Gómez Camacho, Francisco y Robledo Hernández, Ricardo (eds.), El pensamiento económico de la Escuela de Salamanca (Salamanca, Ediciones Universidad de Salamanca), pp. 93-122.

BAsCuñán, Antonio (2004): "La píldora del día después ante la jurisprudencia", en: Revista de Estudios Públicos. Disponible en: http://www.cepchile. cl/1_3389/doc/la_pildora_del_dia_despues_ante_la_jurisprudencia.html\#. U3o5cSnYBOw [visitado el 4 de enero de 2014].

Battaglini, Giulio (1949): Diritto Penale. Parte Generale, $3^{a}$ edición (Padova, Cedam).

Berner, Albert Friedrich (1898): "Lehrbuch des Strafrechts". Disponible en: http://koriath.jura.uni-saarland.de/textsammlung/uploads/Autoren/Berner. pdf [visitado el 9 de enero de 2014].

Biblioteca del Congreso Nacional (2010): “Historia de la Ley No 20.480. Modifica el Código Penal y la Ley № 20.066 sobre Violencia Intrafamiliar, estableciendo el Femicidio, aumentando las penas aplicables a este delito y reforma a las normas sobre Parricidio". Disponible en: http://www.leychile.cl/ Navegar?idNorma=1021343 [visitado el 23 de diciembre de 2013]. 
Cadooppl, Alberto y Veneziani, Paolo (2007): Elementi di Diritto Penale. Parte Generale, $3^{\text {a }}$ edición (Padova, Italia, CEDAM).

Carrara, Francesco (1988): Programa de Derecho Criminal. Parte General (Traducc. José J. Ortega Torres y Jorge Guerrero, Bogotá, Editorial Temis), Volumen I.

Celis SCHWERTER, Lorena Andrea (2001): Análisis jurisprudencial de la eximente de responsabilidad criminal: el que obra violentado por una fuerza irresistible o impulsado por un miedo insuperable, Memoria para optar al grado de licenciado en Ciencias Jurídicas y Sociales (Facultad de Derecho, Universidad de Talca) [inédita].

Cerezo Mir, José (2001): Curso de Derecho penal español. Parte general. Tomo III. Teoría jurídica del delito/2 (Madrid, Tecnos).

Chilesa, Luis E. (2011): "Caso La Mignonette", en: Sánchez-Ostiz Gutiérrez, Pablo (coord.), Casos que hicieron doctrina en Derecho penal (Madrid, La Ley), pp. 95-109.

ChILDS, Penny (2002): Nutcases. Criminal Law, $3^{\text {a }}$ edición (London, Thomson Sweet \& Maxwell).

Coffey, Gerard (2009): "Comment: Codifying the Meaning of 'intention' in the Criminal law", en: The Journal of Criminal Law (Vol. 73, Issue 5), pp. 394-413.

COntIERI, Enrico (1939): Lo stato di necessità (Milano, Giuffrè).

Contreras, Sebastián (2013): "La determinación del Derecho en Domingo de Soto y Francisco Suárez", en: Revista de Estudios Histórico-Jurídicos, Sección Historia del Pensamiento Jurídico. Disponible en: http://www.scielo.cl/pdf/ rehj/n35/a21.pdf [visitado el 22 de abril de 2015].

Córdoba Roda, Juan y Rodríguez Mourullo, Gonzalo (1972): Comentarios al Código Penal. (Barcelona, Editorial Ariel), Tomo I.

Cousiño MAC IVER, Luis (1979): Derecho penal chileno. Parte general (Santiago, Editorial Jurídica de Chile), Tomo I.

Couso Salas, Jaime (2011a): "Comentario al art. 10 № 4 del Código Penal", en: Couso, Jaime y Hernández, Héctor (dirs.), Código Penal Comentado. Parte General. Doctrina y jurisprudencia (Santiago, LegalPublishing), pp. 209-223.

Covarrubias, Diego de (1594): "Tandem in Reg.peccatum.de regu.iur.lib.6.", en: Omnium operum, tomus secundus. Disponible en: http://digibug.ugr. es/handle/10481/10272 [visitado el 22 de agosto de 2014]. 
Cuerda Arnau, María Luisa (1996): “Art. 20.5", en: Vives Antón, Tomás (coord.), Comentarios al Código Penal de 1995 Volumen I (Arts. $1^{\circ}$ a 233) (Valencia, Tirant lo Blanch), pp. 140-162.

CurY, Enrique (2005): Derecho Penal. Parte General, $7^{\text {a }}$ edición (Santiago, Ediciones Universidad Católica de Chile).

(2011): "Estado de necesidad exculpante", en: Seminario del Centro de Estudios Penales de la Universidad de Talca. Disponible en: http://www. ustream.tv/recorded/18539392 [visitado el 2 de marzo de 2011].

(2013): "El estado de necesidad en el Código Penal Chileno", en: AA.VV., La Ciencia Penal en la Universidad de Chile. Libro homenaje a los profesores del Departamento de Ciencias Penales de la Facultad de Derecho de la Universidad de Chile (Santiago, Universidad de Chile), pp. 249-266.

Dobson, Paul (2002): Nutshells. Criminal Law in a Nutshell, 6 a edición (London, Thomson Sweet \& Maxwell).

Etcheberry Orthusteguy, Alfredo (1998a): Derecho Penal, $3^{\text {a }}$ edición (Santiago, Editorial Jurídica de Chile), Tomo I.

Freudenthal, Berthold (2006): Culpabilidad y reproche en el Derecho penal (Traducc. J.L. Guzmán Dalbora, Buenos Aires, Editorial B de f).

Fuentes, Dánae (2009): La ponderación de los males en el estado de necesidad (Santiago, LegalPublishing).

García Cavero, Percy (2011): "Caso de la depresión reactiva", en: Sánchez-Ostiz, Pablo (coord.), Casos que hicieron doctrina en Derecho penal, $2^{\text {a }}$ edición (Madrid, La Ley), pp. 129-142.

García López, Jesús (1990): Individuo, Familia y Sociedad. Los derechos humanos en Tomás de Aquino, $2^{\text {a }}$ edición (Pamplona, Ediciones Universidad de Navarra).

García-Huidobro, Joaquín y Miranda Montesinos, Alejandro (2013): "Sobre la licitud de la destrucción de una aeronave", en: Revista de Derecho, Universidad Católica del Norte (Año 20, № 2), pp. 351-371.

García-Ripoll Montijano, Martín (2006): Ilicitud, culpa y estado de necesidad. Un estudio de responsabilidad extracontractual en los Códigos Penal y Civil (Madrid, Dykinson).

Garofol, Roberto (2008): Manuale di Dirritto Penale. Parte Generale, $4^{a}$ edición (Milano, Giuffrè)

Garrido Montt, Mario (2007b): Derecho Penal. Parte general, 4a edición (Santiago, Editorial Jurídica de Chile), Tomo II. 
GuerRa Espinosa, Rodrigo (2017): Estado de necesidad como conflicto de intereses: una propuesta de interpretación desde la inevitabilidad (Santiago de Chile, Ediciones Olejnik-Ara Editores).

Giulıanı, Ubaldo (1970): Dovere di Soccorso e Stato di Necessità del Diritto penale (Milano, Dott. A. Giuffrè Editore).

Gracianus, Franciscus (1140): Concordantiam Discordantium Canonum seu Decretum Gratiani (Friedberg 1879), en: Internet Service. Disponible en: http://www.documentacatholicaomnia.eu /03d/11391150,_Gratianus_ de_Clusio,_Concordantiam_Discordantium_Canonum_seu_Decretum_ Gratiani_(Friedberg_1879),_LT.pdf [visitado el 22 de junio de 2015].

Greenawalt, Kent (1986): "Distinguishing Justifications from Excuses", en: Law \& Contemporary Problems (Vol. 49, № 3). Disponible en: http://scholarship. law.duke.edu/cgi/viewcontent.cgi?article=3860\&context=lcp [visitado el12 de mayo de 2014].

Grosso, Carlo Federico (1964): Difesa legittima e Stato di Necessitá (Milano, Giuffrè Editore).

Guzmán Dalbora, José Luis (2010): Cultura y delito (Bogotá, Editorial Temis).

HÖRNLE, Tatjana (2010): "Matar para salvar muchas vidas. Casos difíciles de estado de necesidad desde la perspectiva filosófico-moral y jurídico-penal", en: Indret. Disponible en: http://www.indret.com/pdf/744_es.pdf [visitado el 14/10/2013].

HRUSCHKA, Joachim (2005): Imputación y derecho penal. Estudios sobre la teoría de la imputación (Navarra, Editorial Aranzadi).

(2006): La imputación ordinaria y extraordinaria en Pufendorf(Traducc. de Nuria Pastor Muñoz, Colombia, Universidad Externado de Colombia).

Jiménez de AsúA, Luis (1961): Tratado de Derecho penal, 3ª edición (Buenos Aires, Editorial Losada), Tomo IV.

KANT, Immanuel (1968): “Die Metaphysik der Sitten", en: Königlich Preussischen Akademie der Wissenschaften (ed.), Kants Werke. Akademie-Textausgabe. Band VI (Berlin, Walter de Gruyter \& Co.), pp. 203-494.

KINDHÄUSER, Urs (2013): "Acerca de la génesis de la fórmula 'el derecho no necesita ceder ante el injusto'", en: Mañalich, Juan Pablo (coord.), La antijuricidad en el Derecho penal. Estudios sobre las normas permisivas y la legítima defensa (Montevideo-Buenos Aires, Editorial B de f), pp. 65-98.

LaUdien, Theodor (1713): Dissertatio moralis de canone trito: Necessitas non habet legem. Disponible en: https://books.google.es/books?id=ufVFAA 
AAcAAJ\&printsec $=$ frontcover \&hl $=$ es \&.- source $=$ gbs_ViewAPI\&redir esc $=\mathrm{y} \# \mathrm{v}=$ onepage $\& \mathrm{q} \& \mathrm{f}=$ false [visitado el 22 de abril de 2015].

LENCKNER, Theodor (1998): "Anotaciones previas al $\$ 32$ y anotaciones a los $\S \S 32$, 33, 34 y 35 del StGB", en: Schönke-Schröder-StGB, 23 a edición (München, Verlag C.H. Beck), pp. 485-503.

LÖFFLER, Alexander (1901): "Unrecht und Notwehr", Zeitschrift für die gesamte Strafrechtswissenschaft, 21 (Berlín, Manz).

ManzINI, Vicenzo (1933): Trattato di Diritto penale italiano. Secondo il Codice del 1930. Volume Secondo (Torino, Unione Tipografico-Editrice Torinese).

Mañalich, Juan Pablo (2013a): "Normas permisivas y deberes de tolerancia”, en: Mañalich, Juan Pablo (coord.), La antijuricidad en el Derecho penal. Estudios sobre las normas permisivas y la legítima defensa (Montevideo-Buenos Aires, Editorial B de f), pp. 177-283.

Martínez de Ripalda, Juan (1870): "De ente supernaturali". Disponible en: https://books.google.es/books?id=0NxRAAAAcAAJ\&pg=PT318\&dq=ne cessitas+inevitabilis\&hl $=e s \& s a=X \& e i=p 2 p 1 V d b 3 C o H h U L 3 Y g c A B \& r e d$ ir_esc $=\mathrm{y} \# \mathrm{v}=$ onepage $\& \mathrm{q}=$ necessitas $\% 20$ evitabilis\&f=false [visitado el 22 de mayo de 2015].

Marinuccl, Giorgio y DolcinI, Emilio (2006): Manuale de Diritto Penale. Parte generale, $2^{\mathrm{a}}$ edición (Milano, Giuffrè Editore).

Merkel, Reinhart (2000): “La filosofía, i'Convidado de piedra' en el debate del Derecho penal? Sobre la desatención de la dogmática penal a los argumentos filosóficos (y algunos equívocos generalizados a propósito de la cláusula de ponderación de intereses en el estado de necesidad: primer inciso del § 34 StGB)", en: Del Arco Torres, Miguel (dir.), La insostenible situación del derecho penal (Traducc. Pablo Sánchez-Ostiz, Granada, Comares), pp. 181-212.

MIR PUIG, Santiago (2011): Derecho penal. Parte general, $9^{a}$ edición (Barcelona, Reppertor).

Miranda Montecinos, Alejandro (2014): El principio del doble efecto (Hildesheim, Georg Olms Verlag).

Molarl, Alfredo (1964): Profili dello stato di necessità (Padova, CEDAM).

Morales Prats, Fermín (2007): "La exclusión de responsabilidad criminal por concurrencia de causas de justificación: el estado de necesidad", en: QuINTERO Olivares, Gonzalo, Parte General del Derecho Penal, 2a ed., (Pamplona, Aranzadi), pp. 500-520. 
(2011): "Artículo 20.5", en: Quintero Olivares, Gonzalo (dir.),

Comentarios al Código Penal español, 6 a edición (Navarra, Aranzadi), Tomo

I, pp. 220-230

NÁQuira, Jaime (1998): Derecho Penal. Teoría del Delito I (Santiago, Editorial McGrawHill).

OetKer, Frederich (1908): "Notwehr und Notstand", en: Vergleichende Darstellung des deutschen und ausländischen Strafrechts, Allgem Teil. Bd. II (Berlín, Guttentag), pp. 255-395.

Ossandón Widow, María Magdalena (2012): "Aborto y justificación", en: Revista Chilena de Derecho (Vol. 39, № 2), pp. 325-369.

OxMAN, Nicolás (2013): “Una aproximación al sistema de imputación subjetiva en el derecho penal anglosajón”, en: Revista lus et Praxis (Año 19, № 1), pp. 139-194.

Pacheco, Joaquín Francisco (1888): El Código Penal concordado y comentado (Madrid, Imprenta de la Viuda de Perinat y Compañía).

Padovani, Tullio (2006): Diritto penale (Milano, Giuffrè Editore).

Paglaro, Antonio (2003): Principi di Diritto penale. Parte generale, $8^{a}$ edición (Milano, Giuffrè Editore).

Paredes Castañon, José Manuel (1989): "Subsidiariedad y proporcionalidad de los males en el estado de necesidad: El criterio de la exigibilidad (Comentario a la STS del 8 de abril de 1988)", en: Revista del Poder Judicial (Año 1989, No 13), pp. 115-128.

PawLIK, Michael (2002): Der rechtfertigende Notstand (Berlín, Gruyter).

Pennigton, Kenneth (2013): "Moderamen inculpatae tutelae: The Jurisprudence of a Justifiable Defense", en: Rivista Internazionale di Diritto Comune ( $\left.\mathrm{N}^{\circ} 24\right)$, pp. 27-56.

PessoA, Nelson R. (2001): Legítima defensa (Buenos Aires, Mario A. Viera Editor). Politoff Lifschitz, Sergio et al. (2003): Lecciones de Derecho Penal. Parte General. $2^{a}$ edición (Santiago, Editorial Jurídica de Chile), Tomo I.

Quintano Ripollés, Antonio (1946): Comentarios al Código Penal. (Madrid, Editorial Revista de Derecho Privado), Volumen I.

Requejo Conde, Carmen (1999): La legítima defensa (Valencia, Tirant lo Blanch). Rivacoba y Rivacoba, Manuel (1965): "El fundamento a la defensa en la legítima defensa", en: Beristain, Antonio (ed.), Estudios penales, Homenaje al P Julián Pereda, S.J., en su $75^{\circ}$ aniversario (Bilbao, Universidad de Deusto), pp. 249-283. 
Roumy, Franck (2006): "L'origine et la diffusion de l'adage canonique Necessitas non habet legem" (VIIle-XIIIe), en: Müller, Wolfgang y Sommar, Mary (eds.), Medivial church law and the origins of the western legal tradition (Washington D.C., The Catholic University of America Press), pp. 301-319.

Roxin, Claus (1997): Derecho penal. Parte general. Tomo I. Fundamentos de la estructura de la teoría del delito, $2^{a}$ edición (Traducc. D.M. Luzón Peña, Miguel Díaz y García y Javier de Vicente Remesal, Madrid, Civitas).

SÁnchez-Ostiz, Pablo (2012b): Fundamentos de Política criminal. Un retorno a los principios (Madrid, Marcial Pons).

Santibáñez Torres, M. Elena y Vargas Pinto, Tatiana (2011): "Reflexiones en torno a las modificaciones para sancionar el Femicidio y otras reformas relacionadas", en: Revista de Derecho, (Vol. 38, № 1), pp. 193-207.

Schiappol, Domenico (1905): "Diritto penale canonico", en: Pessina, Enrico (coord.) Enciclopedia del diritto penale italiano (Milano, Società Editrice Libraia), Tomo I, pp. 611-967.

Sessano, Camilo (2002): "Código penal italiano". Disponible en: http://www. juareztavares.com/textos/codigoitaliano.pdf [visitado el 23 de de marzo de 2015].

Silva SÁnchez, Jesús María (1998a): Consideraciones sobre la teoría del delito (Buenos Aires, Ad-Hoc).

(1998b): Perspectivas sobre la política criminal moderna (Buenos Aires, Editorial Ábaco de Rodolfo Depalma).

SINGER, Richard y LA FOnd, John (2007): Criminal Law, 4a edición (AustinBoston, Wolter Kluwer).

SIMON, Josef (1977): "Aspectos lingüístico-filosóficos de la historia de la filosofía moderna", en: Simon, Josef (coord.), Aspectos y problemas de la filosofía del lenguajes (Traducc. Ernesto Garzón Valdés, Buenos Aires, Alfa), pp. 20-25.

Sото, Domingo de (1968): De la justicia y del derecho. Libros V y IV (Traducc. P. Marcelino González Ordoñez, Madrid, Instituto de Estudios Políticos), Volumen III.

Stooss, Carl (1899): Bericht Über Den Vorentwurf Zu Einem Schweizerischen Strafgesetzbuck Nach Den Beeschlüssen Der Expertenkommission, Den Holen Eidgenössischen Justizdepartement Erstattet, Parts 1-2 (Nabu Public Domain Reprints).

(1913): Lehrbuch des Österreichischen Strafrechts (Wien un Leipzig, Franz Deuticke). 
SuÁrez, Francisco (1967): Tratado de las leyes y de Dios legislador. (Traducc. José Ramón Eguillor, Madrid, Instituto de Estudios Políticos), Volumen 2.

(1858) Commentaria in secundam secundae divi Thomae, scilicet de fi de, de spe et de charitate disputationes (póstuma, 1621) (París, edición de Ludovicum Vivés).

TADros, Victor (2005): Criminal Responsibility (New York, Oxford University Press).

TIssOt, J. (1875): Introduction historique à l'étude du droit considéré dans les faits ou dans les moeurs, les usages, les institutions et les lois (París, Marescq aîné).

Vargas Pinto, Tatiana (2011): Manual de Derecho penal práctico. Teoría del delito con casos, $2^{a}$ edición (Santiago, LegalPublishing).

Ortiz de Urbina Gimeno, Iñigo de Ortiz (2011): "Caso de los dos psiquiatras en el III Reich", en: Sánchez-Ostiz Gutiérrez, Pablo (coord.), Casos que hicieron doctrina en el Derecho penal, $2^{a}$ edición (Madrid, La Ley), pp. 177-192.

Valle MuÑIz, José Manuel (1992): "Fundamento, alcance y función de las causas de justificación incompletas en el Código Penal español", en: ADPCP, Tomo $X L V$, Fascículo II. Disponible en: http://portal.uclm.es/descargas/idp_docs/ doctrinas/ vallemuniz.pdf [visitado el 22 de julio de 2014].

VeranI, Gaetano Felice (1708): "Iuris Canonici Universi Commentarius Paratitlaris, Seu Dilucida". Disponible en: https://books.google.es/books?id= mnFFAAAAcAAJ\&printsec=frontcover\&hl=es\&source=gbs_ViewAPI\&redir_ $\mathrm{esc}=\mathrm{y} \# \mathrm{v}=$ onepage $\& \mathrm{q} \& \mathrm{f}=$ false [visitado el 22 de abril de 2015].

VILlegas Díaz, Myrna (2010): "Homicidio de la pareja en violencia intrafamiliar. Mujeres homicidas y exención de responsabilidad penal", en: Revista de Derecho, (Vol. XXIII, № 2), pp. 149-174.

Vı, Tomás de (1773): "Commentarium in Summa S. Thomae", en: Aquinatis, Thomae, Summa theologica, cum commentariis Thomae de Vio Card. Cajetani, et elucidationibuslitteralibus P Seraphini Capponi a Porrecta (Roma, s./ed.), pp. 626-631.

WaGner, Paul (1648): "Explicatio regulae: Necessitas non habet legem". Disponible en: https://books.google.es/books?id=eOdIAAAAcAAJ\&printsec $=f$ rontcover\&hl=es\&source=gbs_ViewAPI\&redir_esc $=y \# v=$ onepage \&q\&f=false [visitado el 20/10/2015].

(1725): "Tractatio iuridica qua regula: Necessitas non habet legem ex iure naturali, civili, et canonico". Disponible en: https://books.google. es/books? id=T0xGAAAAcAAJ\&printsec $=$ frontcover \&hl=es \&source $=$ g bs_ViewAPI\&redir_esc $=\mathrm{y} \# \mathrm{v}=$ onepage $\& \mathrm{q}=$ inevitabilis\&f=false [visitado el 4 de junio de 2015]. 
WilenMANN, Javier (2014a): "El fundamento del estado de necesidad justificante en el derecho penal chileno. Al mismo tiempo, introducción al problema de la dogmática del estado de necesidad en Chile", en: Revista de Derecho Valdivia, (Vol. XXVII, No 1), pp. 213-244.

(2014b): "El sistema de derechos de necesidad y defensa en el Derecho penal", en: Indret, Revista para el análisis del Derecho. Disponible en: http:// www.indret.com/pdf/10062.pdf [visitado el 22/12/2014].

(2017): La justificación de un delito en situaciones de necesidad (MadridEspaña, Marcial Pons).

(2016): “La imponderabilidad de la vida humana y situaciones trágicas de estado de necesidad", en: Indret, Revista para el análisis del Derecho. Disponible en: http://www.indret.com/pdf/1201.pdf [visitado el 22/12/2016].

WolfF, Christian (1968): Gesammelte Werke, II. Abt. Lateinische Schriften. Band 22. Jus naturae. Herausgegeben von Marcel Thomann (Hildesheim, Georg Olms).

\section{JURISPRUDENCIA CITADA}

Sentencia de la Corte de Apelaciones de Chillán, 10 de mayo de 1954, RDJ, t. LII, No s. 9 y 10, 1955, secc. cuarta, p. 211.

\section{SENTENCIAS DE PRIMERA INSTANCIA}

Sentencia del Tribunal Oral en lo Penal de San Antonio, 22 de julio de 2008, RIT 49-2008, RUC 0700509932-8.

Sentencia del Sexto Tribunal Oral en lo Penal de Puente Alto, 21 de junio de 2013, causa RUC No 1101060685-5.

\section{SeNTENCIAS EXTRANJERAS}

Sentencia del TSE, 16 de septiembre de 1982, Ponente: Vivas Marzal.

Sentencia del TSE, 8 de diciembre de 1987, Ponente: Díaz Palos.

Sentencia del Reichsgericht, 11 de marzo de 1927, RGSt 63, 211.

Sentencia del Oberster Gerichtshof für die Britische Zone, 5 de marzo de 1949, OGHSt 19-49. 